\title{
ANALYSIS OF PASSING SIGHT DISTANCE USING FIRST-ORDER RELIABILITY METHOD
}

by

\author{
Andres Serrano, BEng \\ Ryerson University \\ Toronto, Ontario, Canada \\ 2014
}

A major research project

presented to Ryerson University

in partial fulfillment of the

requirements for the degree of

Master of Engineering

in the program of

Civil Engineering

Toronto, Ontario, Canada, 2018

(C)Andres Serrano, 2018 


\section{Author's Declaration for Electronic Submission of an MRP}

I hereby declare that I am the sole author of this MRP. This is a true copy of the MRP, including any required final revisions.

I authorize Ryerson University to lend this MRP to other institutions or individuals for the purpose of scholarly research.

I further authorize Ryerson University to reproduce this MRP by photocopying or by other means, in total or in part, at the request of other institutions or individuals for the purpose of scholarly research.

I understand that my MRP may be made electronically available to the public. 


\section{Acknowledgments}

I would like to thank my Supervisor, Dr. Said Easa, for the opportunity to work under his supervision and believing in my academic ability while providing guidance and the advice necessary to complete my Major Research Project. I would also like to extend my deepest gratitude to the Natural Sciences and Engineering Research Council of Canada (NSERC) for funding this undertaking. Finally yet importantly, I would like to thank my family for the support, encouragement and love. 


\author{
Abstract \\ Analysis of Passing Sight Distance Using First-Order Reliability Methods \\ Master of Engineering, 2018 \\ Andres Serrano \\ Yeates School of Graduate Studies, Civil Engineering \\ Ryerson University
}

Current passing sight distance requirements for two lane highways by the American Association of State Highway and Transportation Officials are based on field studies conducted between 1938 and 1941 which use deterministic values for its design variables such as passing sight distance, speed of the passing vehicle, speed differential between the passed and passing vehicle etc. This report presents three methods to analyze reliability and serves as an extension to the revised model presented by Yasser Hassan, Said Easa and A.O.Abd El Halim whose model sought to improve older models by equally considering both observed passing behaviours of drivers and passing maneuvers that are consistent with two lane highways. Analysis of passing sight distance using first order second moment reliability method, advanced first order second moment and the ellipsoid approach to measure the probability of failure of the passing sight distance design, rely solely on the mean and variance (moments) of each randomly distributed variable in contrast to methods that rely only on deterministic values. Results show the advanced first order second moment and the ellipsoid approach provided more accurate results than first order second moment method which in turn provide a greater safety margin with the later also proving to be a much more robust and efficient method of performing a reliability analysis. 
Table of Contents

Author's Declaration for Electronic Submission of an MRP ................................................. ii

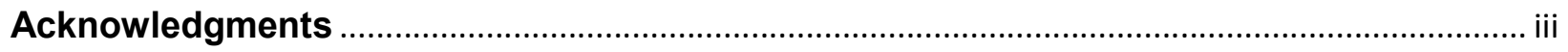

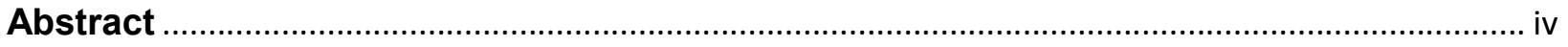

List of Figures:

List of Figures:

1 INTRODUCTION

2 PASSING SIGHT DISTANCE ON TWO-LANE HIGHWAYS ….......................................

2.1 Current Passing Sight Distance Criteria …………….....................................................

2.2 Criteria for No-Passing Zones by Van Valkenburg et al. (1972) .................................... 6

2.3 Passing Sight Distance on Two-Lane Highways: Review and Revision ....................... 9

$3 \quad$ PROBABILITY OF FAILURE AND RELIAIBITLY ANALYSIS .........................................15

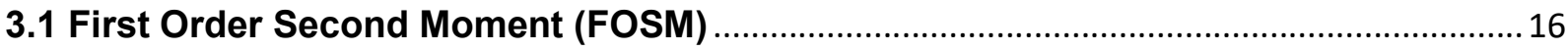

3.2 Advanced First Order Second Moment (AFOSM) ......................................................... 17

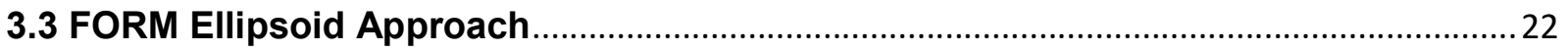

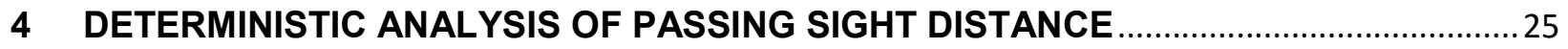

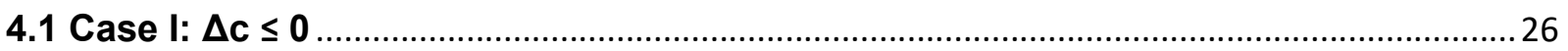

4.2 Case II: $\Delta c \geq 0$

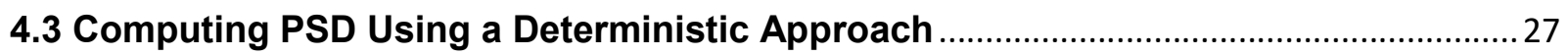

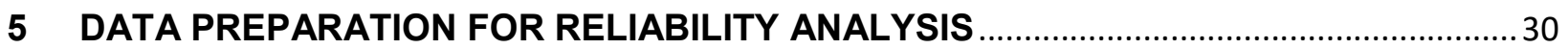




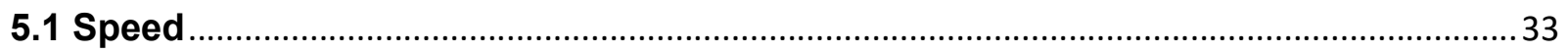

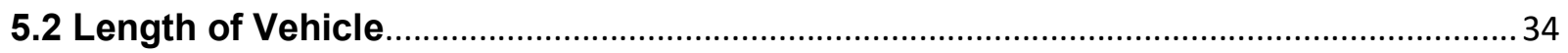

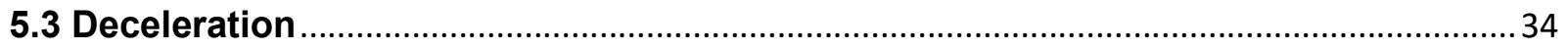

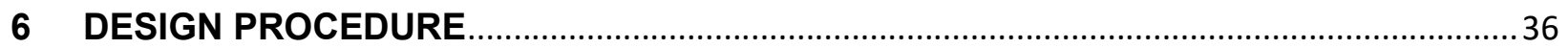

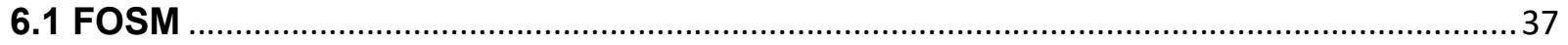

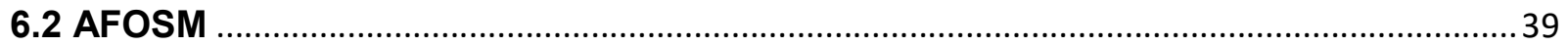

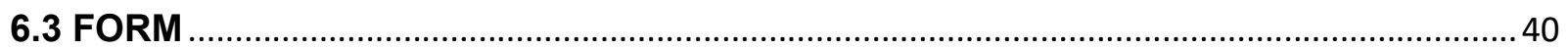

7 VALIDATION OF PROPOSED MODEL USING MONTE CARLO SIMULATION ............... 43

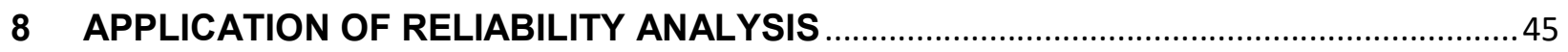

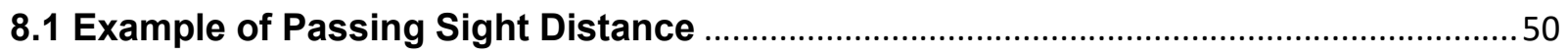

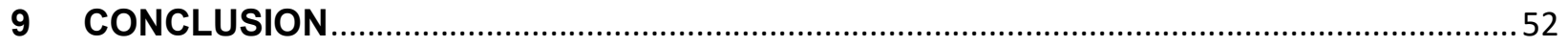

APPENDIX

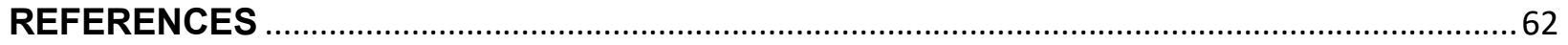




\section{List of Figures:}

Table 1: Four components of the current PSD by AASHTO ........................................................ 5

Table 2: Component $d_{3}$ of the current PSD by AASHTO ............................................................... 5

Table 3: PSD for design on two-lane highways as found in the Green Book (2011) ................... 6

Table 4: Minimum sight distance based on field studies performed by Van Valkenburg and

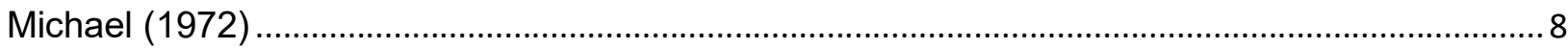

Table 5: Deterministic analysis of Hassan et al (1996) revised model for Scenario 1, when $L_{i}=$

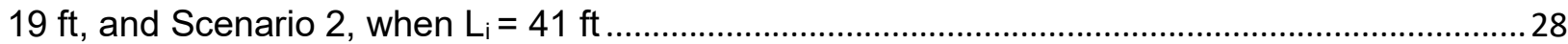

Table 6: Assumed Z-Score of Random Variables including extreme values, mean, and CV ......35

Table 7: $\mathrm{PSD}_{\mathrm{s}}$ for 30 mph for FOSM, AFOSM, and FORM .....................................................50 


\section{List of Figures:}

Figure 1: Time-Space diagram for the revised model by Hassan et al. (1996), (a) Accelerated

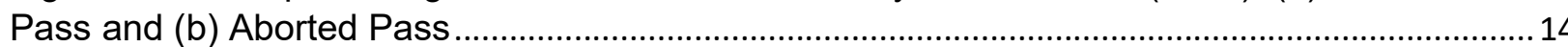

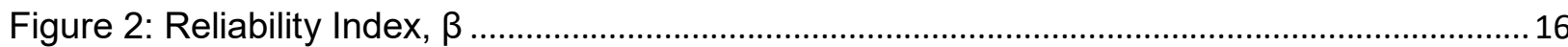

Figure 3: Advanced First Order Second Moment, (a) Original X-Space (b) Transformed U-Space

Figure 4: Flowchart for performing a reverse reliability method for AFOSM (adopted from Du, 2005)

Figure 5: Ellipsoid Approach showing a $1 \sigma$ ellipsoid touching the failure region by a scale of $k$, or in this case the reliability index, $\beta$

Figure 6: Deterministic analysis of Hassan et al (1996) revised model for Scenario 1, when $L_{i}=$

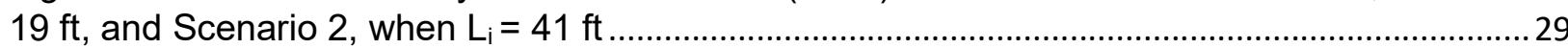

Figure 7: Example of FORM for Case II, the revised model........................................................ 41

Figure 8: Solver Parametres to determine $\mathrm{PSD}_{\mathrm{s}}$ using FORM by Low and Tang ........................42

Figure 9: Histogram of Monte Carlo simulations and the probability distribution of the Monte Carlo Simulation for PSD $(E[G]=717.52 \mathrm{ft}$, of $=317.41 \mathrm{ft}$ and $\beta=2.26)$

Figure 10: Required passing sight distance for a user-specified probability of failure, Pf, for a coefficient of variation $=0.10($ FOSM $)$

Figure 11: Required passing sight distance for a user-specified probability of failure, $\mathrm{Pf}$, for a coefficient of variation $=0.05$ (FOSM)

Figure 12: Required passing sight distance for a user-specified probability of failure, $\mathrm{Pf}$, for a coefficient of variation $=0.10($ AFOSM $)$

Figure 13: Required passing sight distance for a user-specified probability of failure, $\mathrm{Pf}$, for a coefficient of variation $=0.05$ (AFOSM)

Figure 14: Required passing sight distance for a user-specified probability of failure, Pf, for a coefficient of variation $=0.05$ (FORM) 


\section{INTRODUCTION}

Sight distance is among the key elements in achieving efficient and safe operations on highways. According to the American Association of State Highway and Transportation Officials (AASHTO) (2011), highway designers should provide sufficient sight distance to the driver to enable them to control the speed of their cars and avoid colliding into unexpected obstacles on the road.

The Highway Capacity Manual (2016) states that the size of a segment of a two-lane highway depends on the percentage of the segment length available for car maneuvers to avoid obstruction by slow cars on the segment. In this regard, designers should provide passing sight distance at frequent intervals on two-lane highways to allow for overtaking. However, the implementation of this recommendation is faced by challenges since it is not clear how long the passing sight distance should be. Nevertheless, AASHTO provided a model for ascertaining the passing sight distance (PSD), but the model received much criticism from many researchers. Consequently, Van Valkenberg and Michael (1971) argued that a good PSD model should incorporate a trade-off within the sight distance to enable a driver to determine whether to complete or abort the pass.

Passing Sight Distance on Two-Lane Highways: Review and Revision (Hassan, Easa \& Halim, 1996) provides an overview of existing PSD model and aims to provide a revised PSD model that determines PSD more accurately. The AASHTO model came first and received much criticism from authors like Harwood and Glennon (1977) who pointed out the discrepancies in the PSD value for pavement marking provided in the Manual on Uniform Traffic Control Devices (MUTCD) and those on the designs. Similarly, Van Valkenberg and Michael (1971) provided a new concept in modelling PSD, which 
considered dividing the distance travelled by the passing vehicle into two, (1) the distance in which the vehicle can abort the pass $\left(S_{0}\right)$ and (2) the distance required to complete the pass. Van Valkenberg and Michael also address the point past which the pass must be completed as "the point of no return". Lieberman (1982) also applied the same concept in his model. In addition, Glennon (1988) provided a comprehensive model based on the assumption that, "at the beginning of the pass, the sight distance required to abort the pass is much less than that required to complete it, and vice versa, at the end of the pass". Lastly, Rillet et al (1990) revised the Glennon model and addressed a few problems identified in the Glennon model.

Based on the discussed models, the revised model made changes in the mechanism of the passing maneuver, model derivation, and practical considerations. To test the validity of the different models, Hassan et al. (1996) compared the PSD requirements from the various models to the field measurement provided by Van Valkenberg and Michael (1971). The revised model suggests that a passing vehicle should complete its acceleration before reaching the critical position since acceleration at the critical position does not affect the required PSD for speeds higher than $50 \mathrm{~km} / \mathrm{h}$ (31 mph) (Hassan et al, 1996).

In conclusion, it was evident from the review that each model for PSD had inappropriate assumptions that gave longer or shorter PSD requirements. However, a revised model offered a margin of safety for overtaking, which increases as the design speed increases, hence overcoming any deviations from its design values.

PSD plays an importation role in the design and operational efficiency of two-lane highways. PSD is defined as the distance the driver must be able to visually see in order 
to safely and efficiently pass a slower moving vehicle using passing maneuvers in a twolane highway. Currently, National Cooperative Highway Research Program Report 605 (2008) outline current and proposed models of PSD criteria and this report will have a considerable look into the model proposed by Hassan et al. (1996). This major research project will also propose a reliability model using Hassan et al. (1996) model as a base and compare the results against the three reliability methods that are researched. Models that utilize variables such as major-road speed, deceleration rate, perception-reaction time etc. are typically assumed deterministic and this report hopes to capture the randomness that is associated with such variables. 


\section{PASSING SIGHT DISTANCE ON TWO-LANE HIGHWAYS}

\subsection{Current Passing Sight Distance Criteria}

Current PSD criteria for two-lane highways have remained the same since its introduction in the AASHTO policy in 1954. The current PSD criteria is based on field studies that were conducted in 1938 and 1941 that was further validated in 1958. Based on these studies PSD is defined as the sum of four distances:

$$
P S D=d_{1}+d_{2}+d_{3}+d_{4}
$$

Where:

$\mathrm{d}_{1}=$ Distance during the perception and reaction time, including the distance travelled during the initial acceleration of the passing vehicle to the encroachment point

$d_{2}=$ Distance travelled while the passing vehicle occupies the opposing lane

$d_{3}=\quad$ Distance between the passing vehicle and the oncoming vehicle

$d_{4}=\quad$ Distance travelled by the opposing vehicle in the opposing lane for $2 / 3$ of the passing vehicle occupying the lane

The current PSD assumes the passed vehicle travels at a constant speed. As the vehicle approaches the vehicle that is being passed, the vehicle slows down and maintains a speed equal to the passed vehicle. This maneuver is referred to as a delayed pass. Once the passing section is reached, in this case the passing zone as prescribed by the road markings, the driver performing the passing maneuver takes a certain amount of time to perceive the passing zone and begin to accelerate and the passing vehicle accelerates to an average speed difference of $16 \mathrm{~km} / \mathrm{h}$ than that of the passed vehicle. 
The passing maneuver performed by the driver consists of a delayed start and a hurried return denoted by two phases, the first phase and second phase respectively. When the vehicle completes the passing maneuver there should be an adequate clearance between the passing vehicle and the vehicle in the opposing lane. The four components of the current PSD and the Equations are found in Table 1 and Table 2.

Table 1: Four components of the current PSD by AASHTO

\begin{tabular}{|c|c|c|c|c|}
\hline Equation & $\mathrm{d}_{1}$ & $d_{2}$ & $d_{3}$ & $\mathrm{~d}_{4}$ \\
\hline Metric & $0.278 t_{1}\left(v-m+\frac{a t_{1}}{2}\right)$ & $0.278 v t_{1}$ & See Table 2 & $\frac{2}{3} d_{2}$ \\
\hline Imperial & $1.47 t_{1}\left(v-m+\frac{a t_{1}}{2}\right)$ & $1.478 v t_{1}$ & See Table 2 & $\frac{2}{3} d_{2}$ \\
\hline \multicolumn{5}{|c|}{$\begin{array}{l}\mathrm{t}_{1}=\text { time for initial maneuver, } \mathrm{sec} \\
\mathrm{a}=\text { average acceleration, } \mathrm{km} / \mathrm{h} / \mathrm{sec} \text { or } \mathrm{mph} / \mathrm{sec} \\
\mathrm{v}=\text { average speed of passing vehicle, } \mathrm{km} / \mathrm{h} \text { or } \mathrm{mph} \\
\mathrm{m}=\text { difference in speed between passed and passing vehicle } \mathrm{km} / \mathrm{h} \text { or } \mathrm{mph} \\
\mathrm{t}_{2}=\text { time passing vehicle occupies the opposing lane, sec }\end{array}$} \\
\hline
\end{tabular}

Depending on the average speed of the passing vehicle, component $d_{3}$ can be found in Table 2, based on the Green Book (AASHTO 2011). It is important to understand that the speed of the passing vehicle should be used in computing the PSD and not the design speed of the two-lane highway as they differ quite considerable as the passing vehicle's speed largely depends on the speed of the passed vehicle. The speed of the passed vehicle is assumed to represent the average running speed of traffic that can deviate from the design speed of the two-lane highway by as much as $35 \mathrm{~km} / \mathrm{h}$ (22 $\mathrm{mph}$ ) therefore, it is important to accurately represent the speed of the passing vehicle when providing adequate PSD.

Table 2: Component $\mathrm{d}_{3}$ of the current PSD by AASHTO

\begin{tabular}{|c|c|c|c|c|c|c|c|c|}
\hline & \multicolumn{4}{|c|}{ Metric (km/h) } & \multicolumn{4}{|c|}{ Imperial (mph) } \\
\hline $\begin{array}{c}\text { Speed } \\
\text { Range }\end{array}$ & $50-65(30-40)$ & $66-80$ & $81-95$ & $96-110$ & $0-40$ & $40-50$ & $50-60$ & $60-70$ \\
\hline $\mathrm{d}_{3}$ & $30 \mathrm{~m}$ & $55 \mathrm{~m}$ & $75 \mathrm{~m}$ & $90 \mathrm{~m}$ & $100 \mathrm{ft}$ & $180 \mathrm{ft}$ & $250 \mathrm{ft}$ & $300 \mathrm{ft}$ \\
\hline
\end{tabular}


Based on older field studies, the acceleration rate for the initial maneuver ranges from 2.22 to $2.43 \mathrm{~km} / \mathrm{h} / \mathrm{sec}(1.38$ to $1.51 \mathrm{mph} / \mathrm{sec})$ and it was found that $\mathrm{t}_{1}$ and $\mathrm{t}_{2}$ range from $3.6 \mathrm{sec}$ to $4.5 \mathrm{sec}$ and $9.3 \mathrm{sec}$ to $11.3 \mathrm{sec}$ respectively. Many of the values are based on older field studies. The PSD for the design of two-lane highways as found in the Green Book are computed in Table 3.

Table 3: PSD for design on two-lane highways as found in the Green Book (2011)

\begin{tabular}{|c|c|c|c|c|c|c|c|c|c|}
\hline \multicolumn{9}{|c|}{ Metric } & \multicolumn{5}{c|}{ Imperial } \\
\hline $\begin{array}{c}\text { Speed } \\
(\mathrm{km} / \mathrm{h})\end{array}$ & $\begin{array}{c}\text { Assumed speeds } \\
(\mathrm{km} / \mathrm{h})\end{array}$ & \multicolumn{2}{c|}{$\begin{array}{c}\text { Passing Sight } \\
\text { Distance }(\mathrm{m})\end{array}$} & $\begin{array}{c}\text { Speed } \\
(\mathrm{mph})\end{array}$ & $\begin{array}{c}\text { Assumed speeds } \\
(\mathrm{mph})\end{array}$ & $\begin{array}{c}\text { Assumed speeds } \\
(\mathrm{ft})\end{array}$ \\
\hline 30 & 29 & 44 & 200 & 200 & 20 & 18 & 28 & 706 & 710 \\
\hline 40 & 36 & 51 & 266 & 270 & 25 & 22 & 32 & 897 & 900 \\
\hline 50 & 44 & 59 & 341 & 345 & 30 & 26 & 36 & 1088 & 1090 \\
\hline 60 & 51 & 66 & 407 & 410 & 35 & 30 & 40 & 1279 & 1280 \\
\hline 70 & 59 & 74 & 482 & 485 & 40 & 34 & 44 & 1470 & 1470 \\
\hline 80 & 65 & 80 & 538 & 540 & 45 & 37 & 47 & 1625 & 1625 \\
\hline 90 & 73 & 88 & 613 & 615 & 50 & 41 & 51 & 1832 & 1835 \\
\hline 100 & 79 & 94 & 670 & 670 & 55 & 44 & 54 & 1984 & 1985 \\
\hline 110 & 85 & 100 & 727 & 730 & 60 & 47 & 57 & 2133 & 2135 \\
\hline 120 & 90 & 105 & 774 & 775 & 65 & 50 & 60 & 2281 & 2285 \\
\hline 130 & 94 & 109 & 812 & 815 & 70 & 54 & 64 & 2479 & 2480 \\
\hline & & & & & 75 & 56 & 66 & 2578 & 2580 \\
\hline & & & & & 80 & 58 & 68 & 2677 & 2680 \\
\hline
\end{tabular}

\subsection{Criteria for No-Passing Zones by Van Valkenburg et al. (1972)}

Similar to criteria set forth by AASHTO, Valkenburg and Michael (1972) developed a PSD model based on field data and defined PSD as the sum of three distances:

$$
P S D=s_{1}+s_{2}+20
$$

Where:

$\mathbf{s}_{1}=\quad$ Distance traveled by the passing vehicle between the "point of no return" (or critical point) to the point the passing vehicle returns to its respective lane 
$\mathrm{s}_{2}=$ Distance travelled by the opposing vehicle while the passing vehicle occupies the opposing lane

The model is represented in two phases: (1) distance required for the middle of the passing vehicle to become abreast with the rear bumper of the passed vehicle and (2) the distance required for the passing vehicle to perform the passing maneuver from the "point of no return" to the point the passing vehicle returns back to its respective lane. The first phase of the passing maneuver (so) is disregarded from the model as Van Valkenburg and Michael stated that at any point before the critical point the driver of the passing vehicle could apply the brakes and abort the pass.

A passing vehicle can abort the pass at any time up until the point the middle of the vehicle is abreast with the rear bumper of the passed vehicle. Although the critical point was not explicitly stated, the authors did recognize the critical point could vary depending on the speed of the vehicles and/or the speed of the approaching vehicle. Thus, only $s_{1}$ and $s_{2}$

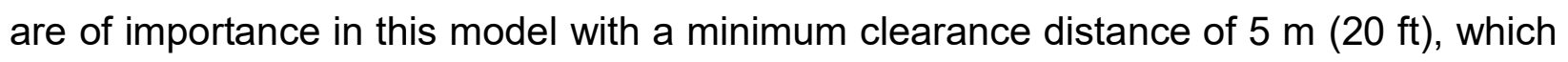
would prevent a head-on collision with a passing vehicle and an opposing vehicle.

Passing sight distance and speeds were determined based on four categories. Before initiating a pass, a vehicle will perform either an accelerative pass or a flying pass. An accelerative pass occurs when the passing vehicles slows down to match the speed of the passed vehicle before it performs the passing maneuver and a flying pass occurs when the passing vehicle does not slow down to match the speed of the passed vehicle before it performs the passing maneuver. Furthermore, the completion and return of the passing vehicle into its lane is either a voluntary or a forced return. 
A voluntary return describes the completion of a pass in which the passing vehicle returns to its respective lane without anything forcing it to return (such as an opposing vehicle or the beginning of a no-passing zone). A forced return refers to the opposite in which the passing vehicle returns to its respective lane due to an opposing vehicle or the beginning of a no-passing zone. Therefore, Van Valkenburg and Michael determined passing sight distances and speeds based on four types of passing maneuvers:

- accelerative pass - voluntary return

- flying pass - voluntary return

- accelerative pass - forced return

- flying pass - forced return

Based on field data collected an accelerative pass with a voluntary return of passing vehicles exhibited a consistently larger length to complete the pass and a lower speed when compared to the other passing maneuvers. Therefore, Van Valkenburg and Michael determined that an accelerative pass with a voluntary return was the most critical and based the minimum sight distance on this type of pass. Table 4 shows the minimum sight distance based on field studies performed by Van Valkenburg and Michael (1972).

Table 4: Minimum sight distance based on field studies performed by Van Valkenburg and Michael (1972)

\begin{tabular}{|c|c|}
\hline $\begin{array}{c}\text { Average off-peak speed } \\
\mathrm{km} / \mathrm{h}(\mathrm{mph})\end{array}$ & $\begin{array}{c}\text { Minimum passing sight distance } \\
\mathrm{m}(\mathrm{ft})\end{array}$ \\
\hline $48(30)$ & $230(750)$ \\
\hline $56(35)$ & $274(900)$ \\
\hline $64(40)$ & $320(1050)$ \\
\hline $72(45)$ & $366(1200)$ \\
\hline $80(50)$ & $396(1300)$ \\
\hline $89(55)$ & $442(1450)$ \\
\hline $97(60)$ & $488(1600)$ \\
\hline $105(65)$ & $533(1750)$ \\
\hline $113(70)$ & $579(1900)$ \\
\hline
\end{tabular}




\subsection{Passing Sight Distance on Two-Lane Highways: Review and Revision}

The revised model developed by Hassan et al. (1996) address many of the shortcomings of previous models for PSD. In particular, Hassan et al. (1996) take into account passing techniques and typical drivers behaviours for passing manoeuvres on a two-lane highway to accurately address the location of the critical position. The authors of this paper determined that in order to accurately provide minimum PSD, two models were required

- dependent on the location of the front of the passing vehicle in relation to the front bumper of the passed vehicle. In other words, the notation of the respective critical position $\left(\Delta_{c}\right)$ determines the model to be utilized.

$$
\begin{aligned}
& \Delta_{c} \leq 0 \\
& \Delta_{c} \geq 0
\end{aligned}
$$

A positive critical position translates to situations where the front bumper of the passing vehicle is ahead of the front bumper of the passed vehicle and a negative critical position translates to situations where the front bumper of the passing vehicle is ahead of the front bumper of the passed vehicle. From a practical standpoint it was determined that in the event that $\Delta_{c} \geq 0$ (when the passing vehicle is ahead of the passed vehicle) a driver cannot be expected to abort a pass. Therefore, when $\Delta_{c} \geq 0$, adequate sight distance should be provided in order for the passing vehicle to complete the pass and the model becomes:

$$
\begin{array}{ll}
P S D=2 v\left(t_{1}+h_{0}\right) & \Delta_{c} \leq 0 \\
P S D=2 v\left(t_{1}^{*}+h_{0}\right) & \Delta_{c} \geq 0
\end{array}
$$


The time-space diagram for the revised model can be found in Figure 1 with the derivation of the PSD based on the time-space diagram.

Hassan et al. (1996) used many of the same assumed values in previous models and are as follows:

- The passed vehicle is travelling at a constant speed of $V-m$ throughout the entirety of the passing maneuver.

- The opposing vehicle is travelling at a constant speed of $\mathrm{V}$ throughout the entirety of the passing maneuver.

- The vehicle that is initiating the pass is traveling at a speed of $V-m$ at that start of the pass. In other words, at the same speed as the impeding vehicle.

- While entering the left lane for a pass, the passing vehicle accelerates at a constant rate, $a$, to speed $V$. The sight distance required is minimal and is well within the range to safely abort the passing maneuver.

- The sight distance for aborting the pass increases as the passing maneuver proceeds and the sight distance for completing the pass decreases as the passing maneuver proceeds as the vehicle reaches the critical position.

In the event the driver perceives a situation in which to about the pass it shall follow specific assumptions:

- A minimum headway, $h_{1}$, should be maintained between the front bumper of the passing vehicle in relation to the rear bumper of the passed vehicle in order to maintain a safe return to the right lane in the event of an abort. 
- A minimum headway, ho, should be maintained between the front bumper of the passing vehicle relative to the front bumper of opposing vehicle relative to the front bumper.

- A perception-reaction time, $\mathrm{p}_{\mathrm{a}}$, is applicable and represents the time it takes the driver to apply the brakes. The speed profile of the vehicle during the driver's perception-reaction time is not affected by the need to abort and is assumed to stay constant.

In the event the driver reaches the critical position, where the sight distance to complete the pass and the sight distance to abort the pass are equal, the following applies:

- Once the critical position, $\Delta_{c}$, is reached it is assumed the passing vehicle has attained a speed equal to $\mathrm{V}$.

- As soon as the driver surpasses the critical position, the driver is in a position where the required sight distance is less to complete the pass than it is to abort the pass.

- The minimum headway, $h_{0} \& h_{1}$, should still be maintained even at the end of the completed pass

The PSD distance is derived from the space-time diagram and is as follows:

$$
\begin{gathered}
\Delta_{c}+v t_{1}=L_{p}+G_{1}+(v-m) t_{1} \text { for a completed pass } \\
\Delta_{c}+v P+v t_{2}-\frac{d t_{2}^{2}}{2}=\left(P+t_{2}\right)(v-m)-L_{l}-G_{2} \text { for an aborted pass }
\end{gathered}
$$

Isolating for $\Delta_{c}$ for Equations (7) and (8), equating them, and solving for $t_{1}$ :

$$
t_{1}=P+t_{2}-\frac{d t_{2}^{2}}{2 m}+\frac{L_{p}+L_{l}+G_{1}+G_{2}}{m}
$$


Similarly, an Equation for PSD can be derived from the space-diagram:

$$
\begin{gathered}
S_{c}=2 v t_{1}+C_{1} \text { for a completed pass } \\
S_{c}=v P+v t_{2}-d t_{2} / 2+v\left(P+t_{2}\right)+C_{2} \text { for an aborted pass }
\end{gathered}
$$

Equating Equations (10) and (11) and solving for $\mathrm{t}_{1}$ :

$$
t_{1}=P+t_{2}-\frac{d t_{2}^{2}}{4 v}-\frac{C_{1}-C_{2}}{2 v}
$$

At this point, equating Equation (9) and (12) and solving for t2:

$$
\begin{gathered}
P+t_{2}-\frac{d t_{2}^{2}}{2 m}+\frac{L_{p}+L_{l}+G_{1}+G_{2}}{m}=P+t_{2}-\frac{d t_{2}^{2}}{4 v}-\frac{C_{1}-C_{2}}{2 v} \\
t_{2}{ }^{2}\left[\frac{d(2 v-m)}{4 v m}\right]=\frac{L_{p}+L_{l}+G_{1}+G_{2}}{m}+\frac{C_{1}-C_{2}}{2 v}
\end{gathered}
$$

By using kinematic equations and the minimum headway the passing vehicle should maintain for both opposing and impending vehicles, $h_{0} \& h_{1}$, respectively the values of $\mathrm{G}_{1}, \mathrm{G}_{2}, \mathrm{C}_{1}$ and $\mathrm{C}_{2}$ are defined as:

For a completed pass:

$$
\begin{aligned}
& G_{1}=(v-m) h_{1} \\
& C_{1}=2 v h_{0}
\end{aligned}
$$

For an aborted pass:

$$
\begin{aligned}
& G_{2}=\left(v-d t_{2}\right) h_{1} \\
& C_{2}=\left(2 v-d t_{2}\right) h_{0}
\end{aligned}
$$

Subbing Equations (15) to (18) into Equation (14) and solving for t2: 


$$
\begin{gathered}
\Delta_{c}=L_{p}+(v-m) h_{1}+m t_{1}=\frac{d t_{2}^{2}}{2}-m\left(P+t_{2}\right)-L_{l}-\left(v-d t_{2}\right) h_{1} \\
t_{1}=P+t_{2}-\frac{d t_{2}^{2}}{4 v}\left(t_{2}+2 h_{0}\right) \\
t_{2}=-\left[\frac{2 v h_{1}-m h_{0}}{2 v-m}\right]+\sqrt{\left[\frac{2 v h_{1}-m h_{0}}{2 v-m}\right]^{2}+\frac{4 v\left[L_{p}+L_{l}+(2 v-m) h_{1}\right]}{d(2 v-m)}}
\end{gathered}
$$

Also:

$$
S_{c}=2 v\left(t_{1}+h_{0}\right)=2 v\left(P+t_{2}+h_{1}\right)-\frac{d t_{2}^{2}}{2}-d t_{2} h_{1}
$$

Hassan et al. (1996) assumed that the minimum headway, $h_{0} \& h_{1}$, are both equal to one s. In other words, for both passing and aborting maneuvers the assumption that $\mathrm{h}_{0}=\mathrm{h}_{1}=\mathrm{h}$ is valid and plugging $\mathrm{h}_{0}=\mathrm{h}_{1}=\mathrm{h}$ into Equations (19) to (22) yields:

$$
\begin{gathered}
\Delta_{c}=L_{p}+(v-m) h+m t_{1}=\frac{d t_{2}^{2}}{2}-m\left(P+t_{2}\right)-L_{l}-\left(v-d t_{2}\right) h \\
t_{1}=P+t_{2}-\frac{d t_{2}^{2}}{4 v}\left(t_{2}+2 h\right) \\
t_{2}=-h+\sqrt{h^{2}+\frac{4 v\left[L_{p}+L_{l}+(2 v-m) h\right]}{d(2 v-m)}} \\
S_{c}=2 v\left(t_{1}+h\right)=2 v\left(P+t_{2}+h\right)-\frac{d t_{2}^{2}}{2}-d t_{2} h
\end{gathered}
$$




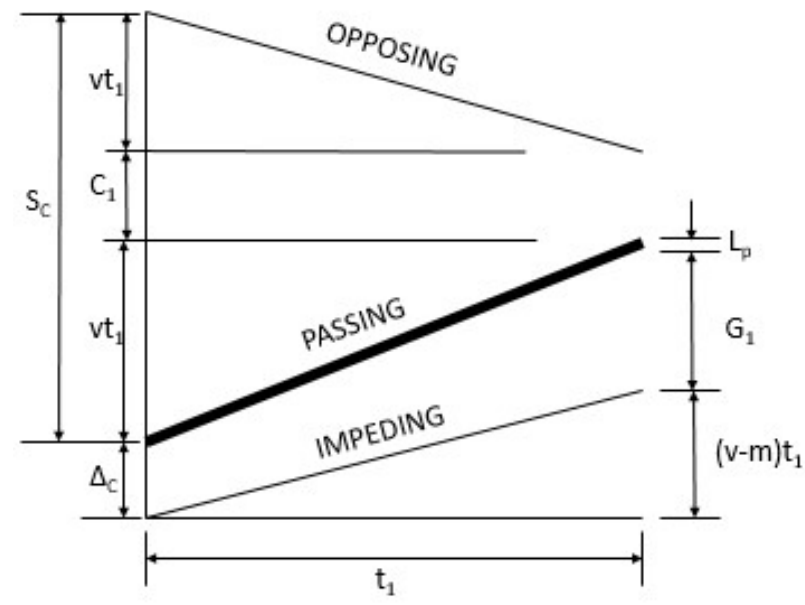

(a)

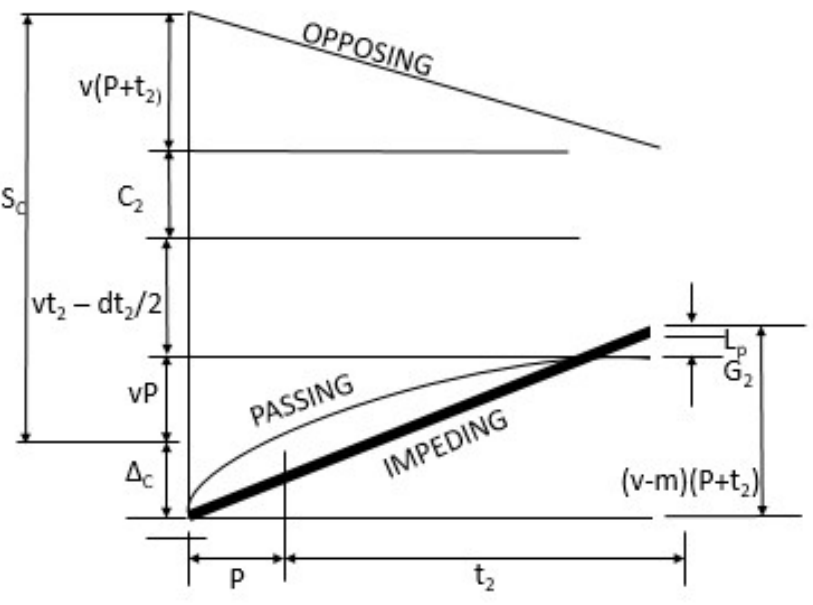

(b)

Figure 1: Time-Space diagram for the revised model by Hassan et al. (1996), (a) Accelerated Pass and (b) Aborted Pass 


\section{PROBABILITY OF FAILURE AND RELIAIBITLY ANALYSIS}

Reliability is defined by the probability of success and is representative of the demand surpassing the capacity of a particular structure or design element. Let $\mathrm{R}$ represent the resistance/capacity (see Figure 2a) of a particular structure/design element and S (see Figure $2 b$ ) represent the applied loading the structure/design element will endure. In this case, failure will occur when the resistance is less than the applied loading. This relationship is represented by the equation $Z=R-S$ and can be seen in Figure 2c.

The probability of failure, $P_{f}$, of the given probability density function (PDF) is $P[(R-S)<$ 0] translating to $P[Z<0]$ with $Z$ being the limit state of the particular reliability analysis being used. There is not enough information on the tails end of the $Z$ distribution and instead the mean value and standard deviation of $Z$ is used, $m z$ and $\sigma z$ respectively. As you can see the in Figure $2 \mathrm{c}$, the distance from the mean of $Z, m z$, to the point of failure (when R-S $=0$ ) is given by the equation $\beta \sigma z$. From this it can be concluded that $m z-\beta \sigma z=$ 0 . Typically, $m_{z}=m_{R}-m_{s}$ and from that $\beta=m_{R}-m_{s} / \sigma z$. $\beta$ has a much more significant meaning than the factor of safety, $F$, as $\beta$ incorporates both the uncertainty related to $R$ and S (Smith, 1986).

This paper provides a reliability analysis using First Order Reliability Method, First Order

Reliability Method, and FORM with speed design graphs for designers to use for a reliability design approach to passing sight distance. 


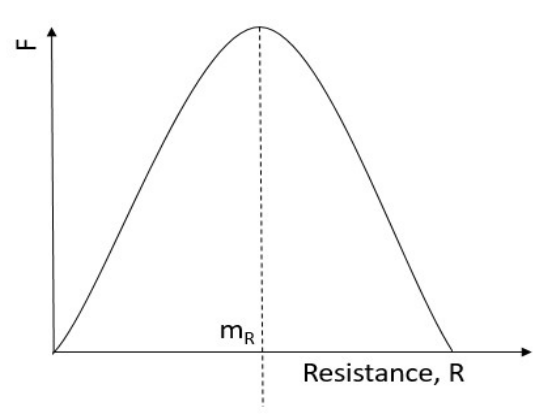

(a)

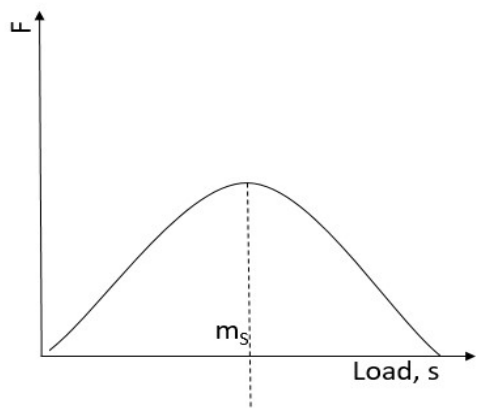

(b)

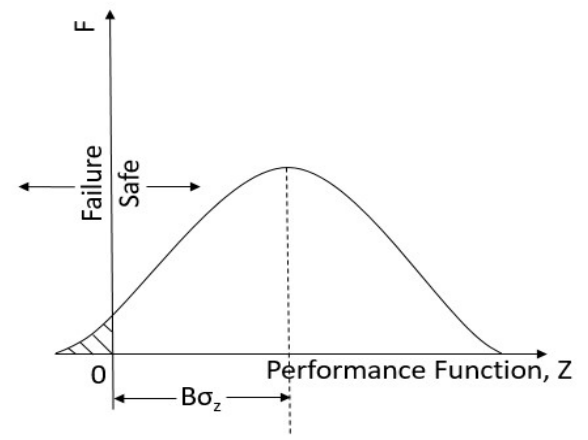

(c)

Figure 2: Reliability Index, $\beta$

\subsection{First Order Second Moment (FOSM)}

The performance function $\mathrm{Z}$ is a function of $n$ random variables as follows:

$$
Z=g(X)=g\left(X_{1}, X_{2}, \ldots, X_{n}\right)
$$

By transforming a non-linear function into a linear function through Taylor series expansion, an approximate linear function for the performance function is as follow:

$$
Z=f(X)+\sum_{i=1}^{n} \frac{\partial g}{\partial X_{i}}\left(X_{i}-x_{i}^{*}\right)+\sum_{i=1}^{n} \sum_{j=1}^{n} \frac{\partial^{2} g}{\partial X_{i} \partial X_{j}}\left(X_{i}-x_{i}^{*}\right)\left(X_{j}-x_{j}^{*}\right) \ldots
$$

The design point, $\mathrm{X}^{*}$, corresponds to the value at which $\mathrm{X}$ will be approximated when using the first order second moment method. The design point in this case is the mean and the first order second moment method refers to the Taylor series expansion on the mean value. Using only the first order terms and using Taylor series expansion about the mean:

$$
X=\left(X_{1}, X_{2}, \ldots, X_{n}\right)=\left(x_{1}^{*}, x_{2}^{*}, \ldots, x_{n}^{*}\right)
$$

Evaluated at $\left(x_{1}^{*}, x_{2}^{*}, \ldots, x_{n}^{*}\right)=\left(\mu_{1}, \mu_{2}, \ldots, \mu_{n}\right)$

$$
Z=g\left(\mu_{1}, \mu_{2}, \ldots, \mu_{n}\right)+\sum_{i=1}^{n}\left(X_{i}-\mu_{i}^{*}\right) g^{\prime}\left(x_{i}\right)
$$


The mean and variance of $Z, \mu z$ and $\sigma^{2} z$, are given by:

$$
\begin{aligned}
& \mu_{Z}=g\left(\mu_{X_{1}}, \mu_{X_{2}}, \ldots, \mu_{X_{n}}\right) \\
& \sigma_{Z}^{2}=\sum_{i=1}^{n} \sum_{j=1}^{n} \frac{\partial g}{\partial X_{i}} \frac{\partial g}{\partial X_{j}} \operatorname{Cov}\left(X_{i}, X_{j}\right)
\end{aligned}
$$

In the case of uncorrelated random variables, $\sigma^{2} z$ becomes:

$$
\sigma_{Z}^{2}=\sum_{i=1}^{n}\left(\frac{\partial f}{\partial X_{i}}\right)^{2} \operatorname{Var}\left(X_{i}\right)
$$

From the mean and variance of $Z$, one can then estimate the reliability index mentioned previously:

$$
\beta=\frac{\mu_{Z}}{\sigma_{Z}}
$$

\subsection{Advanced First Order Second Moment (AFOSM)}

The Advanced First Order Second Moment (AFOSM) method, referred to as the 'HasoferLind' method, uses the transformation of a problem to a standardized coordinate system in order to assess the reliability index as depicted in Figure 3 . The transformation/reduction of a random variable $X_{i}$ is as follow:

$$
U_{i}=\frac{\left(X_{i}-\mu_{x_{i}}\right)}{\sigma_{x_{i}}}
$$

For a standard variable, $U_{i}$, the mean is equivalent to zero with a standard deviation of unity. The transformation formula can be used to transform the original limit state function $Z=g(X)$ into a reduced limit state surface $Z=g(U) . X$ refers to the original coordinate system and $U$ refers to the standardized coordinate system. For a performance function of two random variables $\mathrm{X}_{1}$ and $\mathrm{X}_{2}$ in $\mathrm{X}$-space: 


$$
\begin{aligned}
& X_{1}=U_{1} \sigma_{1}+\mu_{1} \\
& X_{2}=U_{2} \sigma_{2}+\mu_{2}
\end{aligned}
$$

Given a function $\mathrm{g}(\mathrm{x})$ in X-space,

$$
g\left(X_{1}, X_{2}\right)=X_{1}-X_{2}
$$

And transforming to $\mathrm{g}(\mathrm{U})$ in $\mathrm{U}$-space,

$$
g\left(U_{1}, U_{2}\right)=\left(U_{1} \sigma_{1}+\mu_{1}\right)-\left(U_{2} \sigma_{2}+\mu_{2}\right)
$$

In AFOSM method, the reliability index $\beta$ is the minimum distance from the limit state surface, in $U$-space, to the origin of the axis in the reduced coordinate system $(0,0)$.

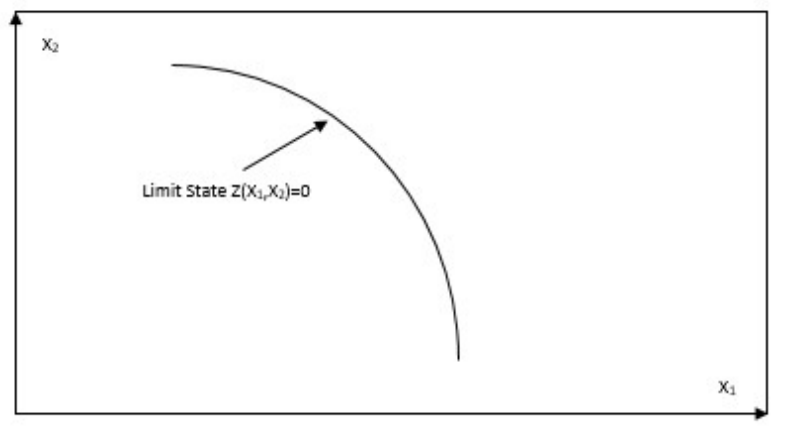

a)

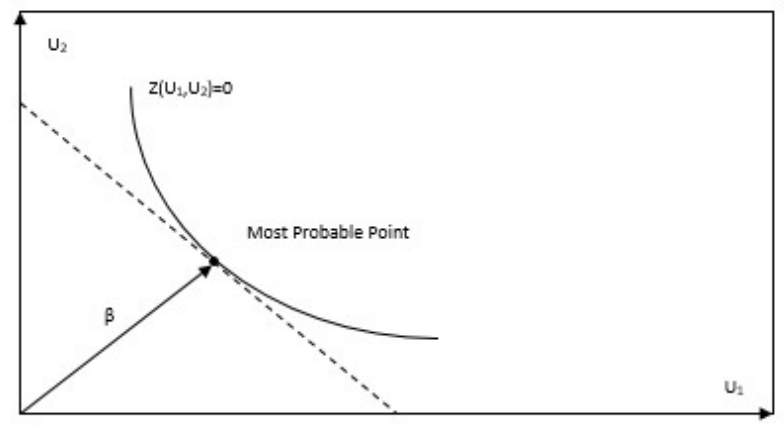

b)

Figure 3: Advanced First Order Second Moment, (a) Original X-Space (b) Transformed U-Space

The minimum distance point on the limit state surface is the design point i.e. the most probable point. As previously mentioned, the design point is denoted by $\mathrm{x}^{*}$ in the original coordinate system from Equation (29). In the reduced coordinate system, the design point is denoted by $u^{*}$. In the case of non-linear limit state surfaces, the assessment of $\beta$ becomes an optimization written as

$$
\text { minimize } \beta=\sqrt{U^{T} U}
$$




$$
\text { subject to } g\left(U_{1}, U_{2}, \ldots, U_{n}\right)=0
$$

A stepwise approaching in determining the reliability index follows a numerical algorithm:

1. Ensure the performance function is in terms of uncorrelated random variables and follow a normally distributed function. Smith (1986) outlines the procedure to transform the space of correlated variables into a non-correlated space. This is done by transforming a covariance matrix into its corresponding normalise modal matrix, $\mathrm{N}$, through Jacobi's method. This method of transformation involves the product of the rotational matrices used to determine the eigenvalues of a covariance matrix.

2. Transform random variables in $X$-space to $U$ space, using Equation (35).

3. Set $u^{0}=(0)$ and $\beta^{0}=0$ to start the algorithm. $u$ and $\beta$ are updated with each new iteration.

4. Begin the first iteration by solving for $Z\left(u^{0}\right)$ in the transformed space

5. Find the gradient of $\nabla Z\left(u^{0}\right)$ by determining the partial derivative for the transformed random variables, $\mathrm{U}_{\mathrm{i}}$, at $u^{0}=(0)$

$$
\nabla Z\left(u^{0}\right)=\left(\frac{\partial f}{\partial U_{1}}, \frac{\partial f}{\partial U_{2}}, \ldots, \frac{\partial f}{\partial U_{i}}\right)
$$

6. Find $\alpha_{i}$, directional cosines, alone the coordinate axes at $u^{0}=(0)$ given by

$$
\alpha_{i}=\frac{\nabla Z\left(u^{0}\right)}{\left\|\nabla Z\left(u^{0}\right)\right\|}=\frac{\left(\frac{\partial f}{\partial U_{1}}, \frac{\partial f}{\partial U_{2}}, \ldots, \frac{\partial f}{\partial U_{i}}\right)}{\sqrt{\sum_{i=1}^{n}\left(\frac{\partial f}{\partial U_{i}}\right)^{2}}}
$$

7. Find unew

$$
u_{i}{ }^{1}=-\alpha_{i}\left[\beta^{0}+\frac{Z\left(u^{0}\right)}{\left\|\nabla Z\left(u^{0}\right)\right\|}\right]
$$


8. Find $\beta_{\text {new }}$

$$
\beta^{1}=\sqrt{\left(u_{i}^{1}\right)^{2}}
$$

9. Now $\beta^{1}=>\beta^{0}$ and $u_{i}{ }^{1}=>u_{i}{ }^{0}$ and continue steps 3-8 until convergence.

The above formulation is similar to the procedure covered by Smith (1986) algorithm that converges to the most probable point quickly. Instances requiring a reverse probability problem where $\beta$ is known, the performance function in the standardized coordinate is equal to zero for $u_{i}^{\beta}$. Therefore, $Z\left(u_{i}^{\beta}\right)$ is equal to zero and Equation (44) becomes

$$
u_{i}^{1}=-\alpha_{i} \beta
$$

by setting $u^{0}=(0)$ and keeping $\beta$ a constant value. Once convergences of $u_{i}$ occurs the algorithm can be stopped. Figure 4 is a flowchart that shows a visual representation of the steps required in a reverse reliability instance $(\mathrm{Du}, 2005)$. It is important to work in the reduced or normalised space, which is this case, is referred to as the U-Space. Reduced variables have properties where its mean is equal to zero the standard deviation is unity. Using reduced variable the axis the variable occupies becomes the mean with a standard deviation of one. 


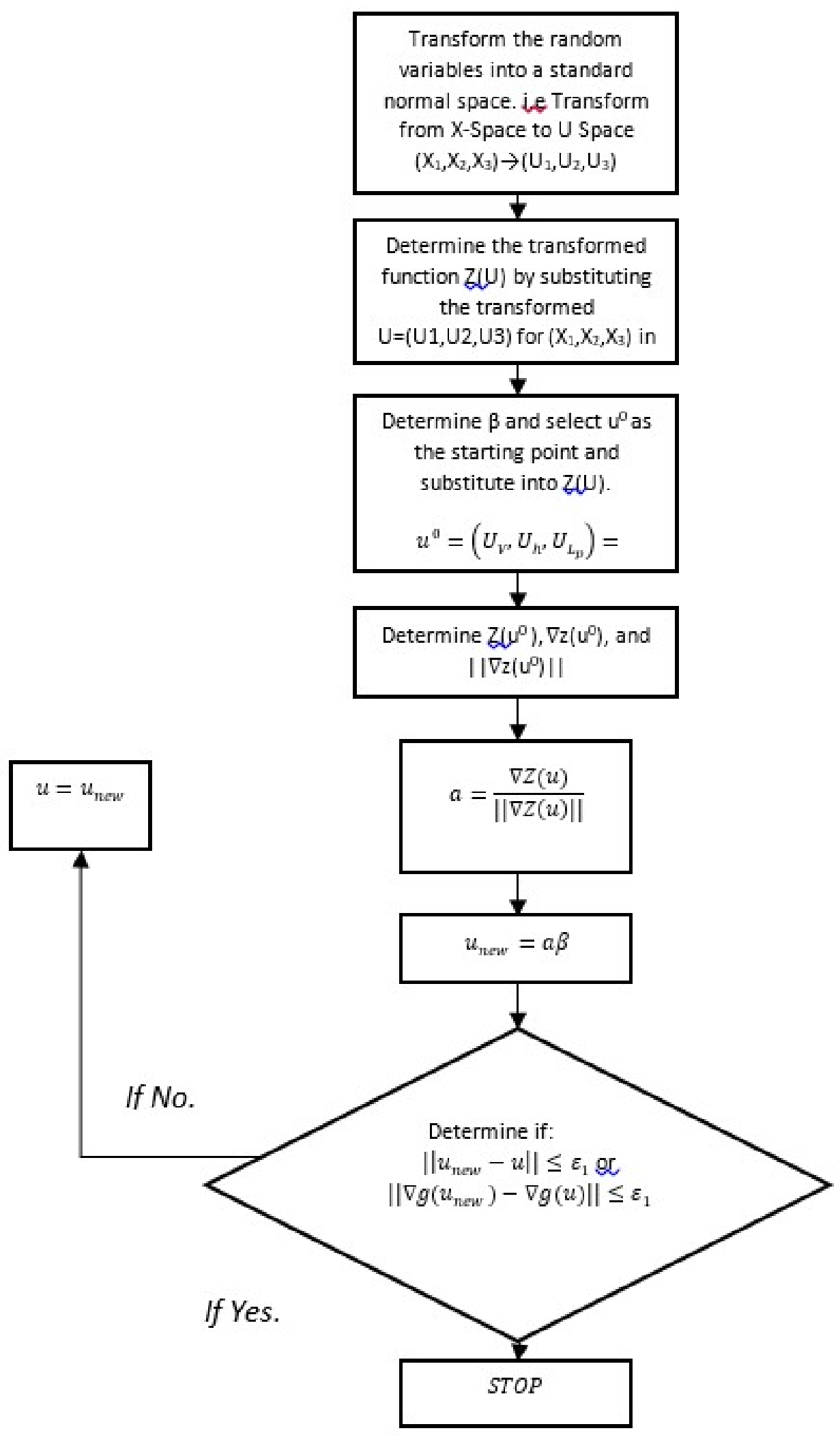

Figure 4: Flowchart for performing a reverse reliability method for AFOSM (adopted from Du, 2005) 


\subsection{FORM Ellipsoid Approach}

Low and Tang (2007) proposed the ellipsoid approach for calculating reliability index of a performance function. The ellipsoid approach, unlike the AFOSM, works in the original space and involves an ellipsoid touching the limit state surface as seen in Figure 5.

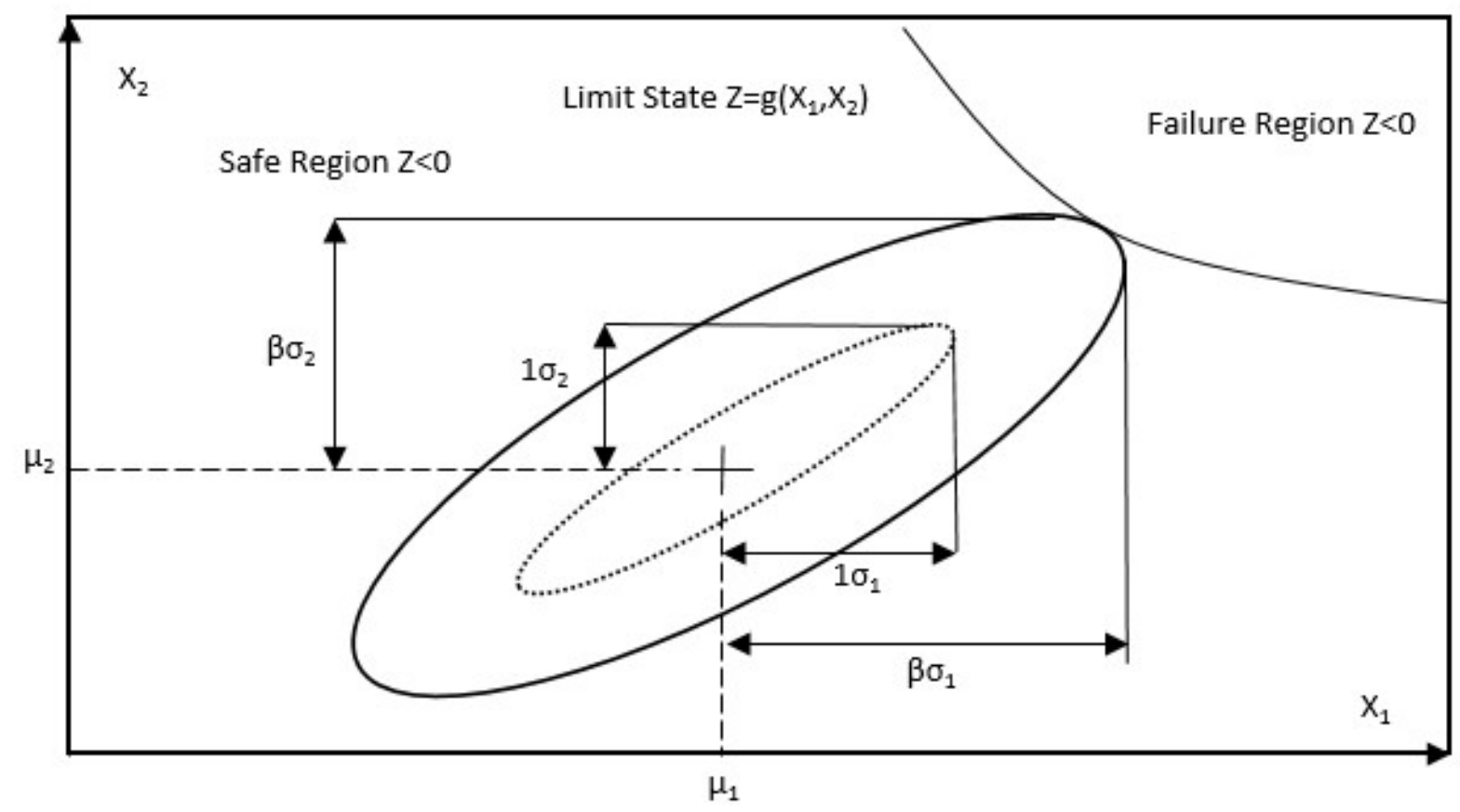

Figure 5: Ellipsoid Approach showing a $1 \sigma$ ellipsoid touching the failure region by a scale of $k$, or in this case the reliability index, $\beta$

The formulation of reliability index by Hasofer and Lind (1974) expressed in matrix formulation is given by:

$$
\beta=\min _{X \epsilon F} \sqrt{(X-\mu)^{T} C(X-\mu)}
$$

Where:

$\mathrm{Y}=\quad$ vector of the random variable

$X=\quad$ mean values of the random variables 
$\mathrm{C}=$ covariance matrix corresponding to the random variables

Setting $\beta=1$, Equation 47 becomes

$$
1=(X-\mu)^{T} C(X-\mu)
$$

For a performance function of two random variables, $\mathrm{X}_{1}$ and $\mathrm{X}_{2}$, in matrix notation formulation:

$$
1=\left[\begin{array}{ll}
\left(X_{1}-\mu_{1}\right) & \left(X_{2}-\mu_{2}\right)
\end{array}\right]\left[\begin{array}{cc}
\sigma_{1}^{2} & \rho \sigma_{1} \sigma_{2} \\
\rho \sigma_{1} \sigma_{2} & \sigma_{2}^{2}
\end{array}\right]^{-1}\left[\begin{array}{l}
X_{1}-\mu_{1} \\
X_{2}-\mu_{2}
\end{array}\right]
$$

and simplified to,

$$
1=\frac{\left(X_{1}-\mu_{1}\right)^{2}}{\left(1-\rho^{2}\right) \sigma_{1}^{2}}+\frac{\left(X_{2}-\mu_{2}\right)^{2}}{\left(1-\rho^{2}\right) \sigma_{2}^{2}}-\frac{2 \rho\left(X_{1}-\mu_{1}\right)\left(X_{2}-\mu_{2}\right)}{\left(1-\rho^{2}\right) \sigma_{1} \sigma_{2}}
$$

Equation (50) represents the $1 \sigma$ dispersion ellipse for 2 correlated normal variables. Assuming the dashed ellipse in Figure 5 is the $1 \sigma$ dispersion ellipse, the $1 \sigma$ dispersion ellipse expands (or contracts), without any change to the original width to height ratio, until it reaches the limit state surface $Z=g(X)=0$. The $1 \sigma$ dispersion ellipse is centred around the $\mu_{i}$ with aspect ratios equivalent to $\sigma_{i}$ of the random variables.

To better understand the ellipsoid approach, Low and Tang (2007) determined that the size of the ellipse at any point can be determined by substituting $k \sigma_{1}$ and $k \sigma_{2}$ for $\sigma_{1}$ and $\sigma_{2}$ respectively. By multiplying $\sigma_{i}$ by a constant value this keeps the original aspect ratio of the $1 \sigma$ dispersion ellipse.

$$
k^{2}=\frac{\left(X_{1}-\mu_{1}\right)^{2}}{\left(1-\rho^{2}\right) \sigma_{1}^{2}}+\frac{\left(X_{2}-\mu_{2}\right)^{2}}{\left(1-\rho^{2}\right) \sigma_{2}^{2}}-\frac{2 \rho\left(X_{1}-\mu_{1}\right)\left(X_{2}-\mu_{2}\right)}{\left(1-\rho^{2}\right) \sigma_{1} \sigma_{2}}
$$


Equation (51) shows the results after substituting $\mathrm{k}$ and after simplifying, it is evident that the value of $k$ corresponds to the reliability index, $\beta$. A design vector $X^{*}$ defines the corresponding coordinate vector for the ellipse tangent to the limit state function and the most probable point in this approach corresponds to the smallest ellipse tangent to the limit state surface. By setting constraints $Z\left(X_{1}, X_{2}\right)=0$ Equation (51) transforms to:

$$
\begin{aligned}
& \text { minimize } \beta=\sqrt{\frac{\left(X_{1}^{*}-\mu_{1}\right)^{2}}{\left(1-\rho^{2}\right) \sigma_{1}^{2}}+\frac{\left(X_{2}^{*}-\mu_{2}\right)^{2}}{\left(1-\rho^{2}\right) \sigma_{2}^{2}}-\frac{2 \rho\left(X_{1}^{*}-\mu_{1}\right)\left(X_{2}^{*}-\mu_{2}\right)}{\left(1-\rho^{2}\right) \sigma_{1} \sigma_{2}}} \\
& \text { subject to } Z\left(X_{1}, X_{2}\right)=0
\end{aligned}
$$

Equation (52) can be solved for any number of random non-normal variables as an optimization problem by using the SOLVER tool in excel and setting the constraint of the performance function $Z=0$. The benefit of this method and spreadsheet computation is that it works in the original space. Low and Tang (2007) have also developed a VBA module that considers the distribution of a random variable along with the required parameters. This saves the need to change non-normal variables into equivalent normal mean and equivalent normal standard deviation and performs the iterative computations in the VBA module. 


\section{DETERMINISTIC ANALYSIS OF PASSING SIGHT DISTANCE}

The revised model developed by Hassan et al. (1996) address many of the shortcomings of previous models for PSD. In particular, the model takes into consideration passing techniques and typical driver behaviours for passing manoeuvres on a two-lane highway that accurately address the location of the critical position. The authors of this paper consider two general cases to establish minimum PSD that is dependent on the location of the front of the passing vehicle in relation to the front bumper of the passed vehicle during the passing maneuver. In other words, the sign of the respective critical position $\left(\Delta_{c}\right)$ determines the model to be utilized, as follows:

CASE I: $\Delta_{c} \leq 0$

CASE II: $\Delta_{c} \geq 0$

Where:

$\Delta_{\mathrm{C}}=$ relative position of the passing vehicle with respect to the impeding vehicle measured from front bumper to front bumper (ft)

A positive critical position translates to situations where the front bumper of the passing vehicle is ahead of the front bumper of the passed vehicle and a negative critical position translates to situations where the front bumper of the passing vehicle is ahead of the front bumper of the passed vehicle. From a practical standpoint it was determined that in the event that $\Delta_{c} \geq 0$, when the passing vehicle is ahead of the passed vehicle, a driver cannot be expected to abort a pass. Therefore, when $\Delta_{c} \geq 0$, the passing vehicle is ahead of the impeding vehicle, adequate sight distance is required for the passing vehicle to complete 
the pass or when $\Delta_{c} \leq 0$, adequate sight distance is required for the driver to abort the pass. The model becomes,

$$
\begin{array}{ll}
P S D=2 v\left(t_{1}+h_{0}\right) & \Delta_{c} \leq 0 \\
P S D=2 v\left(t_{1}^{*}+h_{0}\right) & \Delta_{c} \geq 0
\end{array}
$$

Where:

$\mathrm{V}=\quad$ speed of the passing vehicle $(\mathrm{mph})$

$t_{1}=\quad$ time required to pass the impeding vehicle from the critical position and return to its own lane (sec)

$\mathrm{h}=\quad$ minimum headway between the passing vehicle and impeding vehicle at the end of the completed maneuver. Similarly, minimum headway between the passing vehicle and oncoming vehicle in the opposing and at the end of the completed maneuver (sec).

\subsection{Case I: $\Delta \mathrm{c} \leq 0$}

The following equations apply to instances when the front bumper of the passing vehicle is behind the front bumper of the impeding vehicles and given by

$$
\begin{aligned}
& t_{2}=-h+\sqrt{h^{2}+\frac{5.88 V\left[L_{p}+L_{l}+1.4(2 V-m) h\right]}{1.47 d(2 V-m)}} \\
& t_{1}=p+t_{2}-\frac{d t_{2}^{2}}{4 V}\left(t_{2}+2 h\right)
\end{aligned}
$$

Where:

$\mathrm{t}_{2}=\quad$ time required to abort a passing maneuver $(\mathrm{sec})$ 
$L_{p}=\quad$ length of the passing vehicle $(\mathrm{ft})$

$\mathrm{L}_{\mathrm{i}}=\quad$ length of the impeding vehicle $(\mathrm{ft})$

$\mathrm{m}=\quad$ speed differential between the passing vehicle and impeding vehicle $(\mathrm{mph})$

$p=$ perception-reaction time required by the driver to decide to abort a passing maneuver

$d=\quad$ deceleration rate used by driver in the passing vehicle to abort a passing maneuver $\left(\mathrm{ft} / \mathrm{sec}^{2}\right)$

\subsection{Case II: $\Delta c \geq 0$}

Equation 58 applies in cases when the front bumper of the passing vehicle is ahead of the front bumper of the impeding vehicle. According to Hassan et al. (1996), drivers in this position are unlikely to abort the pass. Therefore, setting $\Delta_{c}=0$ provides adequate sight distance for the vehicle to complete a passing maneuver as

$$
t_{1}^{*}=\frac{1.47(V-m) h+L_{p}}{1.47 m}
$$

Where:

$t^{*}{ }_{1}=$ time required to pass the impeding vehicle from the critical position and return to its own lane (sec)

\subsection{Computing PSD Using a Deterministic Approach}

Table 5 shows PSD using a deterministic analysis of Hassan et al. (1996) model. The critical position at various speeds was determined considering two scenarios: (1) a car measuring $19 \mathrm{ft}$ passing another car measuring $19 \mathrm{ft}$ and (2) a car measuring $19 \mathrm{ft}$ passing a truck measuring $41 \mathrm{ft}$. From Table 4, it can be concluded that in most cases, speeds 
greater than $54 \mathrm{mph}$ indicate when the passing vehicle's position is ahead of the front bumper of the impeding vehicle.

Table 5: Deterministic analysis of Hassan et al (1996) revised model for Scenario 1, when $\mathrm{L}_{\mathrm{i}}=19 \mathrm{ft}$, and Scenario 2, when $\mathrm{L}_{\mathrm{i}}=41 \mathrm{ft}$

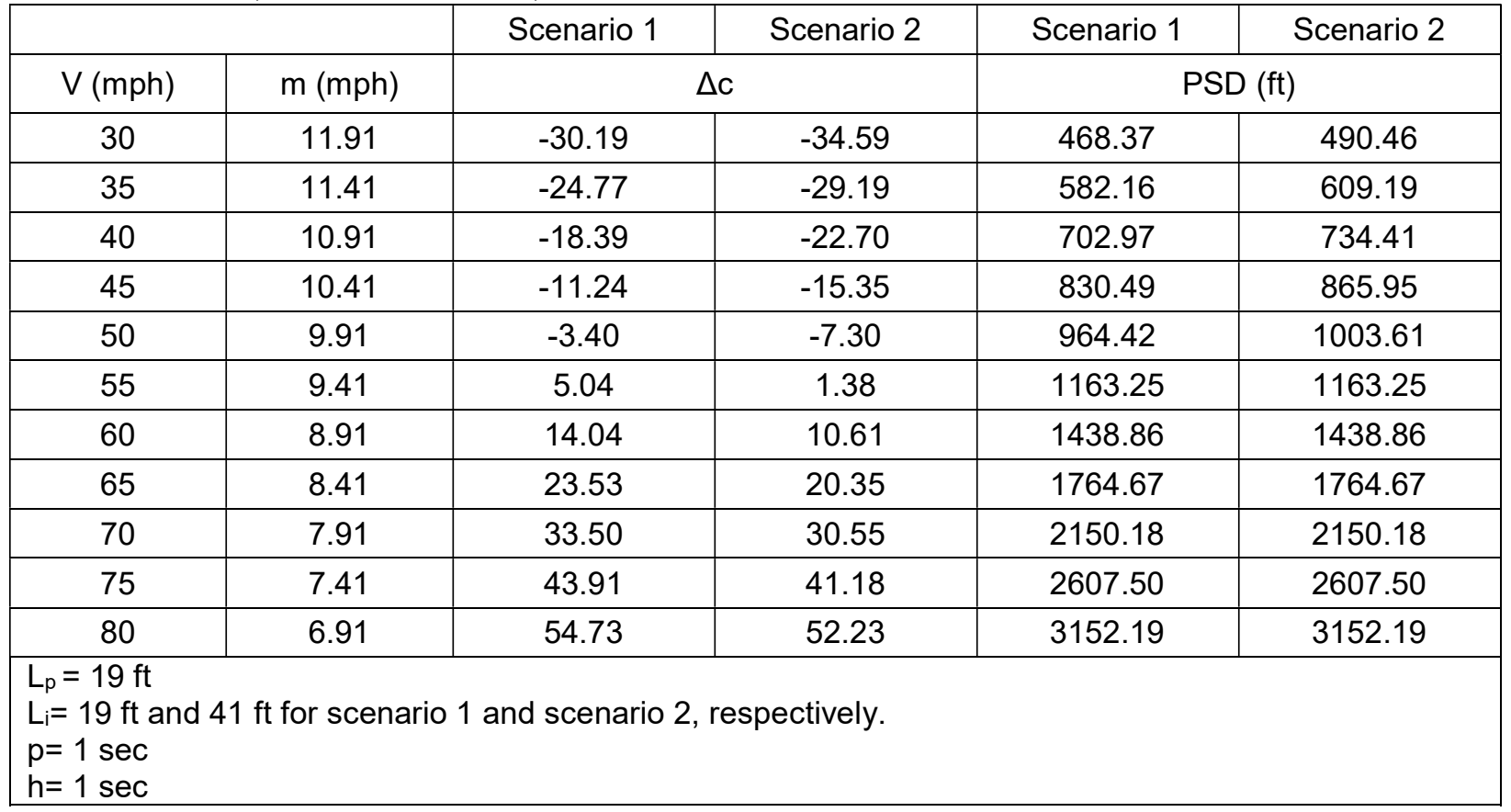

PSD for scenario 2 has a higher PSD for a greater length of impeding vehicle. Due to the longer length of the impeding vehicle, more distance is required to either abort or complete the maneuver. Despite the change in PSD from Scenario 1 to Scenario 2, the effect vehicle length has on PSD is minimal. Lastly, impeding vehicle length has no effect for Case II when the critical position is greater than zero. This is expected as the vehicle is already positioned in front of the other impeding vehicle and is expected to complete the passing maneuver. Therefore, the truck length has no effect on the time required to pass the impeding vehicle from the critical position and return to the lane. The deterministic analysis is important as it gives an indication of when to apply either Case I or Case II for reliability analysis. For simplicity, Case II will be applied to speeds greater 
than $55 \mathrm{mph}$ and a reliability analysis will be performed using FOSM, AFOSM, and FORM while Case I will be applied to speeds less than $55 \mathrm{mph}$ as indicated in Figure 6 .

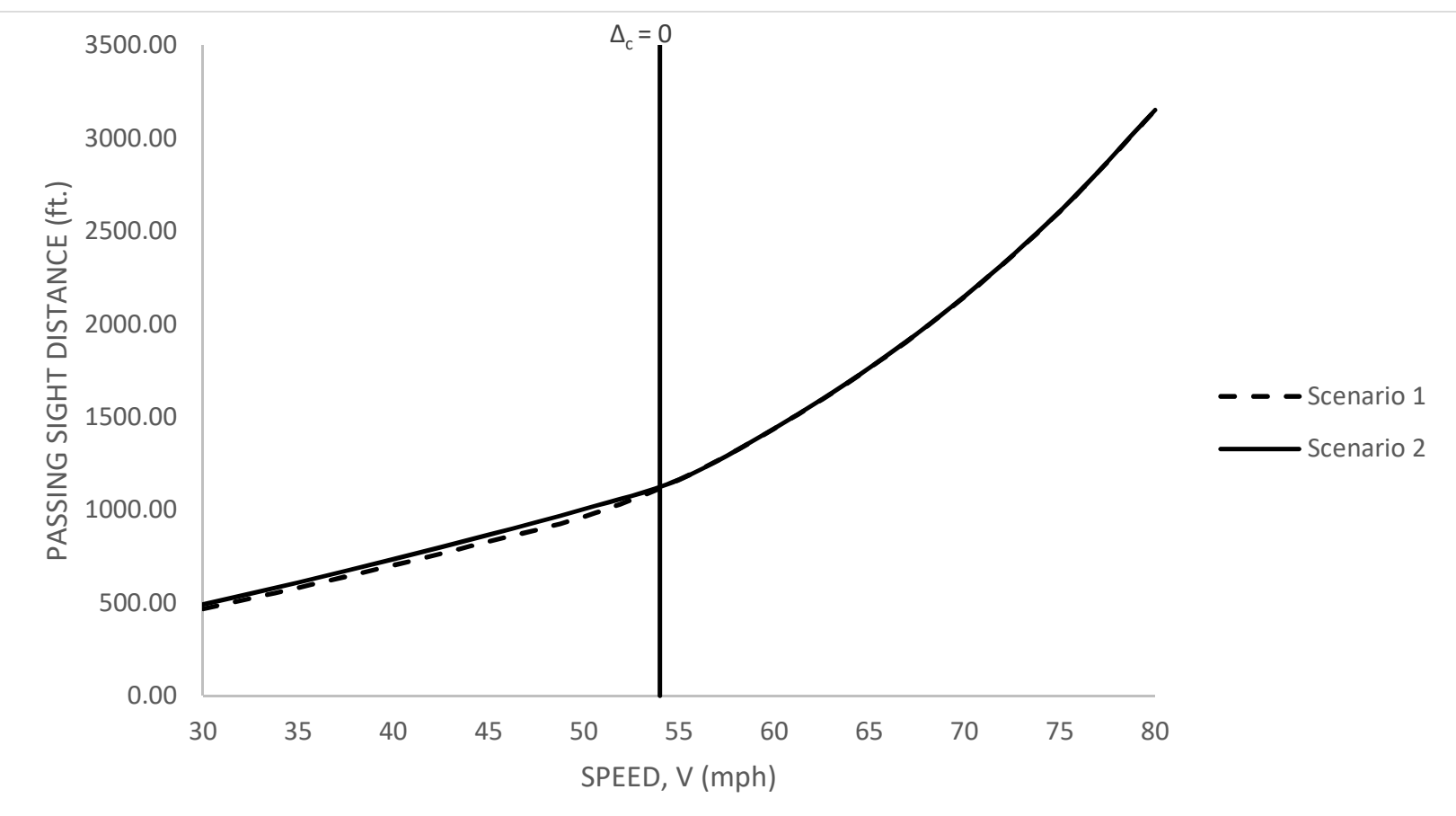

Figure 6: Deterministic analysis of Hassan et al (1996) revised model for Scenario 1, when $L_{i}=19 \mathrm{ft}$, and Scenario 2, when $L_{i}=41 \mathrm{ft}$ 


\section{DATA PREPARATION FOR RELIABILITY ANALYSIS}

In the current deterministic method, $\mathrm{V}$, is assumed to be design speed in $\mathrm{mph}$, and $\mathrm{h}$ and $P a$ are assumed to be $1 \mathrm{sec}, L$ is assumed to be $19 \mathrm{ft}$, and $d$ is assumed to be $8 \mathrm{ft} / \mathrm{sec}^{2}$. The following reliability analysis of PSD will depend on random variables $V, L$ and $d$ with the assumption that there is no correlation amongst any of the variables. For this reliability analysis, only a passing maneuver corresponding to a forced return is considered. For a forced return the minimum headway required is assumed to be $1 \mathrm{sec}$, simplifying the equation further, $P S D$ is given by:

$$
P S D=-\frac{2.93 V^{2}+1.99 V L_{p}}{0.1 V-14.91}
$$

When designing for PSD it is important to choose a headway of $1 \mathrm{sec}$ corresponding to a forced return. Values larger than $1 \mathrm{sec}$ indicate a voluntary return and headway for a voluntary return can be large and result in PSD of considerable length. A large PSD from a voluntary return is a result of a more than sufficient time for the passing vehicle to return to the lane as the opposing vehicle is far. Therefore, for design purposes the minimum headway is a constant, corresponding to $1 \mathrm{sec}$. This means that for Case II, the reliability method will depend on the speed and length of the passing vehicle only. Equation (59), only applies to Case II and hereon after, equations for case II will be shown due to the simplicity of deriving the equations required for the reliability analysis. The performance function $G$ for the reliability analysis can then be defined as:

$$
\begin{gathered}
p_{f}=P\left\{G=P S D_{s u}-P S D_{d} \leq 0\right\} \\
p_{f}=P\left\{G=P S D_{s u}+\frac{2.93 V^{2}+1.99 V L_{p}}{0.1 V-14.91} \leq 0\right\}
\end{gathered}
$$


$P_{f}$ is defined as the probability that performance function $G$ is less than zero. In order for this to be true, the demand passing sight distance must be larger than the supply passing sigh distance. MATLAB is used to compute the safety margin/performance function and derivation of Case I equations following the same procedure and the code is outlined in the Appendix.

Similar to headway, perception - reaction time for the driver to decide to abort a passing maneuver was assumed to be $1 \mathrm{sec}$ mainly due to the condition that a driver deciding to abort a passing maneuver is fully aware of the obstacle in front of them. Wortman and Matthias (1983), determined that the perception reaction time differed depending on two conditions,

(1) an alerted return or,

(2) a surprised return.

In both instances, drivers were reacting to a traffic light turning yellow. The perception reaction time differed from 0.9 and $1.3 \mathrm{sec}$, respectively, based on an $85^{\text {th }}$ percentile. Drivers performing a passing maneuver will typically perform a pass with clear view of the opposing lane and well aware of any impeding vehicles within its path and as such can be considered an alerted return. This value can vary depending on the passing conditions of the road and can be higher than the assumed $1 \mathrm{sec}$. Such a case exist where finite passing sight distance is given near an intersection or a peak in the geometry of the road resulting in surprised conditions.

For the purpose this study, it is assumed there is an infinite amount of sight distance available to the driver to properly react to an opposing vehicle. $1 \mathrm{sec}$ is also reasonable 
when one considers the environment the passing vehicle is experiencing. In most cases, it is assumed that the driver will react almost instantly to an impeding vehicle and therefore choose to react at a reasonably fast rate and abort the passing maneuver if it so chooses (Harwood et al., 2008).

For a proposed reliability method, the parameters are considered random variables with a mean value, a standard deviation and a probability distribution. In instances where there is a lack of data on the mean, standard deviation and correlation of the random variables, extreme values can be used to infer these values in order to perform a reliability analysis. Assuming a normal distribution of the random variables, the relationship between mean and extreme values is given by:

$$
\mu_{X_{i}}=\frac{E_{X_{i}}}{1+Z C V_{X_{i}}}
$$

Where:

$\mu x_{i}=$ mean value

$E_{x i}=$ extreme value relating to a specified percentile of a random variable

$Z=\quad Z$-score relating to $a$ specified percentile of a random variable

$C \mathrm{X}_{\mathrm{i}}=$ assumed coefficient of variation

The area under the standard normal curve found normally with tables, can be used for $P_{f}$ $>0.1$. However, the table cannot be used for the standard normal variate of values corresponding to a $\mathrm{P}_{\mathrm{f}}$ less than 0.1 due to inaccuracy. A least-squares approximation can be used and given by:

$$
\beta=-0.615+\left[0.378-2.199\left(0841+\ln P_{f}\right)\right]^{0.5}
$$




\subsection{Speed}

Many field studies were conducted of the passing process for vehicles in two-lane highways addressing speeds in different sections of the passing maneuver. A study done by Llorca et al. (2014) used both static and dynamic methodologies for 8 two-lane highway segments in Valencia collecting the passing vehicle's initial speed. It was found that the speed of the passing vehicle for a sample size of 150 to have a mean initial speed of 71.1 $\mathrm{km} / \mathrm{h}$ with a standard deviation of 10.4 . The posted speed limit of the observed highways was not specified. Another study done by Carlson et al. collected data on two-lane highways with posted speed limits in the range of $80-90 \mathrm{~km} / \mathrm{h}$ and found them to have a mean of $68.3 \mathrm{mph}$ for a vehicle passing a vehicle travelling at $55 \mathrm{mph}$.

Additionally, previous field studies cover only a small range of two lane highways but most studies seem to ignore the initial starting speed before the vehicle initiates the passing maneuver. Therefore, for the purpose of the paper, the desired speed or the design speed will be used under the assumption that most passing maneuvers occur at speeds equal to or greater that the posted limit. This assumption is conservative, as most drivers performing a passing maneuver will typically do so at a greater speed than the passed vehicle. This assumption also follows the ASSHTO (2011) model based on a delayed beginning and hurried return where the passing vehicles speed is greater than the overtaken vehicle by $15 \mathrm{~km} / \mathrm{h}$. Therefore, for the purpose of this field study, passing speed was based on a high percentile, in this case the $99^{\text {th }}$ percentile with a Z-score equivalent to 2.32 . 


\subsection{Length of Vehicle}

For the purpose of this study, the passing maneuver was based on two light vehicles for the passing vehicle and the impeding vehicle. According to a survey by the United States Census Bureau of Vehicle Inventory and Use Survey and the FHWA Highway Statics 2002, light vehicles amount to $91 \%$ of traffic with a length of $19 \mathrm{ft}$. Assuming the vehicle length represents a high percentile of ( $99^{\text {th }}$ percentile) a Z-score equivalent to 2.32 was used.

\subsection{Deceleration}

Hassan et al. (1996) provided a procedure for determining the average time-dependent deceleration rate by assuming the initial value of $d$ and solving for $t 2$. The final speed can then be acquired by solving for $v-d t$ that can then be used to determine the average deceleration rate based on a user-defined model for deceleration rate. A model to acquire a time-depended deceleration rate was suggested by the authors, however, the assumption that deceleration is time-dependent is outdated. Fambro et al. (1997) suggested a constant deceleration rate of $8 \mathrm{ft} / \mathrm{sec}^{2}$ independent of speed. Furthermore, a constant deceleration of $11.1 \mathrm{ft} / \mathrm{sec}^{2}$ was adopted by the Green Book (AASHTO, 2011) for a controlled stop based on their studies. The decision to abort a passing maneuver is done so with adequate sight distance. Therefore, any oncoming traffic while the passing vehicle occupies the left lane is visible and therefore, the act of aborting a pass can be completed in a controlled environment.

The NCHRP (Harwood et. al, 2008) also recommends this value with special care given towards using a higher deceleration rate. In order to warrant a higher deceleration rate, it 
is recommended that data be collected first as a higher deceleration rate will lead to smaller values of passing sight distances. . Assuming the deceleration represents a low percentile ( $5^{\text {th }}$ percentile), a Z-score equivalent to -1.64 was used. In this case, where there is infinite PSD, it is safe to assume that a higher deceleration rate is possible as the driver will have more than adequate time to decide to slow down.

Table 6: Assumed Z-Score of Random Variables including extreme values, mean, and CV

\begin{tabular}{|c|c|c|c|c|c|}
\hline Variable & $\begin{array}{c}\text { Extreme Value } \\
\left(E_{x_{i}}\right)\end{array}$ & $\begin{array}{l}\text { Mean Value } \\
\left(\mu \mathrm{x}_{\mathrm{i}}\right)^{\mathrm{a}}\end{array}$ & $Z^{b}$ & $\begin{array}{l}\text { Coefficient of } \\
\text { Variation }\left(C V_{x_{i}}\right)\end{array}$ & Case I or II \\
\hline$V^{a, b}$ & Varies & Varies & 2.32 & 0.5 or 0.1 & $\mathrm{I}, \mathrm{II}$ \\
\hline$L^{a, b}$ & $19 \mathrm{ft}$ & 17.03 or 15.42 & 2.32 & 0.5 or 0.1 & $\mathrm{I}, \mathrm{II}$ \\
\hline$d^{a, b}$ & $8 \mathrm{ft} / \mathrm{sec}^{2}$ & 8.71 & -1.64 & 0.5 or 0.1 & II \\
\hline $\mathrm{Pa}^{\mathrm{c}}$ & $1 \mathrm{sec}$ & - & - & - & II \\
\hline $\mathrm{h}^{\mathrm{c}}$ & $1 \mathrm{sec}$ & - & - & - & $\mathrm{I}, \mathrm{II}$ \\
\hline
\end{tabular}




\section{DESIGN PROCEDURE}

The aforementioned model for Case II remains true either on the basis that the passing vehicle's bumper is abreast or ahead of the impeding vehicle's bumper. In this case, the vehicle is expected to complete the passing maneuver and adequate PSD should be provided. The time to complete the maneuver and have the passing vehicle return to its own lane is given by:

$$
t_{1}^{*}=\frac{1.47(V-m) h+L_{p}}{1.47 m}
$$

Where:

$t^{*}{ }_{1}=$ time required to pass the impeding vehicle from the critical position and return to its own lane (sec).

Now the required passing sight distance for vehicles in Case II is given by:

$$
P S D=2.93 V\left(t_{1}^{*}+h\right) \quad \Delta_{c} \geq 0
$$

Where:

$V=\quad$ speed of the passing vehicle $(\mathrm{mph})$

$t_{1}=\quad$ time required to pass the impeding vehicle from the critical position and return to its own lane (sec)

$\mathrm{h}=$ minimum headway between the passing vehicle and impeding vehicle at the end of the completed maneuver. Similarly, minimum headway between the passing vehicle and oncoming vehicle in the opposing and at the end of the completed maneuver (sec). 
Therefore, the final equation for PSD is given by:

$$
\begin{aligned}
& P S D=2.93 V\left[\frac{1.47(V-m) h+L_{p}}{1.47 m}+h\right] \\
& P S D=2.93 V\left[\frac{1.47 V h-1.47 m h+L_{p}}{1.47 m}+h\right] \\
& P S D=2.93 V\left[\frac{V h}{m}-h+\frac{L_{p}}{1.47 m}+h\right] \\
& P S D=\frac{2.93 V^{2} h+1.99 V L_{p}}{m}
\end{aligned}
$$

This equation can be further simplified by utilizing an equation provided by Hassan et al. (1996) to represent the differential speed:

$$
P S D=-\frac{2.93 V^{2} h+1.99 V L_{p}}{0.1 V-14.91}
$$

A study done by Polus et al. (2000) confirm that the speed differential between the overtaken vehicles was not constant like AASHTO (2011) assumes and that it decreases with an increase in speed.

\subsection{FOSM}

First order second moment method is defined by the performance function $G$ and defined as:

$$
Z=P S D_{S u}-P S D_{D}
$$

Where PSDs and $\mathrm{PSD}_{\mathrm{D}}$ are the supplied and demanded passing sight distance, respectively. The probability of failure, mean (expected value) and variance of $\mathrm{G}$ are given below: 


$$
\begin{gathered}
E[Z]=P S D_{S U}-E\left[P S D_{d}\right] \\
\operatorname{var}[Z]=\sum_{i=1}^{n}\left(\frac{\partial f}{\partial X_{i}}\right)^{2} \sigma_{x_{i}}^{2}+\sum_{i \neq j}^{n} \sum_{j \neq i}^{n} \frac{\partial f}{\partial X_{i}} \frac{\partial f}{\partial X_{j}} \operatorname{Cov}\left(X_{i}, X_{j}\right)
\end{gathered}
$$

Assuming no correlation amongst any of the variables, the variance of $G$ is simplified into

$$
\operatorname{var}[Z]=\left(\frac{\partial f}{\partial V}\right)^{2} \sigma_{V}^{2}+\left(\frac{\partial f}{\partial L_{p}}\right)^{2} \sigma_{L p}^{2}
$$

Where:

$$
\begin{aligned}
& \frac{\partial f}{\partial V}=\frac{-2930 V^{2}+873726 V+296709 L_{p}}{(10 V-1491)^{2}} \\
& \frac{\partial f}{\partial L_{p}}=-\frac{1.99 L_{p}}{0.1 V-14.91}
\end{aligned}
$$

And finally

$$
\begin{gathered}
\beta=\frac{E[Z]}{\sigma_{Z}} \\
E[Z]=\beta \sigma_{Z}=\beta \sqrt{\operatorname{var}[Z]}
\end{gathered}
$$

As mentioned before, the headway is assumed as a deterministic variable. The var[G] can be computed by using Equation (69) in conjunction with the partial derivatives in Equation (70) and (71). For FOSM, the design point is the mean of the random normal variables with the mean and standard deviations attained in the previous section for the speed and length of passing vehicle that is used to determine var[G] and E[PSDD]. With a specified probability of failure, $P_{f}$, the reliability index, $\beta$, can be computed using Equation (71). Now all the necessary components are determined and the supplied 
passing sight distance can be computed by rearranging Equation (73) and substituting for $E[G]$, as follows

$$
P S D_{S u}=E[Z]+\beta \sqrt{\operatorname{var}[Z]}
$$

\subsection{AFOSM}

The probability is defined as the probability the allowable PSD value is less that the supplied passing sight distance. Using Equation (35) and transforming $V$ and $L$ into reduced variables and assuming the random variables are normally distributed, $\mathrm{V}$ and $\mathrm{L}$ become:

$$
U=\left(U_{V}, U_{L}\right)=\left(\frac{V-\mu_{V}}{\sigma_{V}}, \frac{L-\mu_{L}}{\sigma_{L}}\right)
$$

Or,

$$
U=(V, L)=\left(\mu_{V_{d}}+U_{V} \sigma_{V}, \mu_{L}+U_{L} \sigma_{L}\right)
$$

Therefore, the transformation function in U-space becomes:

$$
\begin{gathered}
Z(U)=S_{S}+\frac{2.93\left(\mu_{V}+U_{V} \sigma_{V}\right)^{2}+1.99\left(\mu_{V}+U_{V} \sigma_{V}\right)\left(\mu_{L}+U_{L} \sigma_{L}\right)}{0.1\left(\mu_{V}+U_{V} \sigma_{V}\right)-14.91}=0 \\
S_{S}=-\frac{2.93\left(\mu_{V}+U_{V} \sigma_{V}\right)^{2}+1.99\left(\mu_{V}+U_{V} \sigma_{V}\right)\left(\mu_{L}+U_{L} \sigma_{L}\right)}{0.1\left(\mu_{V}+U_{V} \sigma_{V}\right)-14.91} \\
\frac{\partial f}{\partial U_{V}}=\frac{1.99 \sigma_{V}\left(\mu_{L p}+U_{L} \sigma_{L}\right)+5.86 \sigma_{V}\left(\mu_{V}+U_{V} \sigma_{V}\right)}{\gamma}-\frac{2.93 \sigma_{V}\left(\mu_{V}+U_{V} \sigma_{V}\right)^{2}+1.99 \sigma_{V}\left(\mu_{L}+U_{L} \sigma_{L}\right)\left(\mu_{V}+U_{V} \sigma_{V}\right)}{10^{2}}
\end{gathered}
$$

Where:

$$
\gamma=0.1\left(\mu_{V}+U_{V} \sigma_{V}\right)-149.1
$$

and, 


$$
\frac{\partial f}{\partial U_{L}}=\frac{1.99 \sigma_{L}\left(\mu_{V}+U_{V} \sigma_{V}\right)}{0.1\left(\mu_{V}+U_{V} \sigma_{V}\right)-149.1}
$$

The gradient of $Z(U)$ is given by

$$
\begin{gathered}
\nabla Z(U)=\left(\frac{\partial f}{\partial U_{V}}, \frac{\partial f}{\partial U_{L}}\right) \\
|| \nabla Z(U)||=\sqrt{\left(\frac{\partial f}{\partial U_{V}}\right)^{2}+\left(\frac{\partial f}{\partial U_{L_{p}}}\right)^{2}}
\end{gathered}
$$

At this point an iterative procedure will take place in order to determine the MPP, $u^{*}$, where the performance function $Z(U)$ is minimized. This procedure was previously discussed in Section 3.2.

\subsection{FORM}

Low and tang provided guidance on performing a reliability analysis using the ellipsoid approach by using Excel Solver that essentially minimizes Equation (92). Low and Tang (2007) have managed to optimize and improve computation power with the following formula that is then used to solve for the reliability index:

$$
\beta=\min \sqrt{\left[\frac{x_{i}-m_{i}}{\sigma_{i}}\right]^{T}[R]^{-1}\left[\frac{x_{i}-m_{i}}{\sigma_{i}}\right]}
$$

The process Low and Tang (2007) provided was meant to perform a reliability analysis to determine the reliability index. For this paper however, the reverse is needed and therefore the process needs to be manipulated further in the Excel Solver to determine

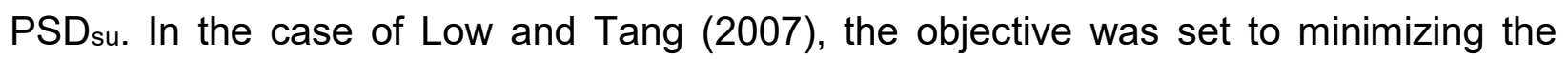


reliability index cell and setting the performance function equal to zero while only changing variable cells $\mathrm{n}_{\mathrm{i}}$. For the reverse reliability, the objective was set to the "Supply" cell in column $\mathrm{C}$ and maximized in order to find the supply corresponding to the worst case for the respective reliability index. These cells carried the solution only.

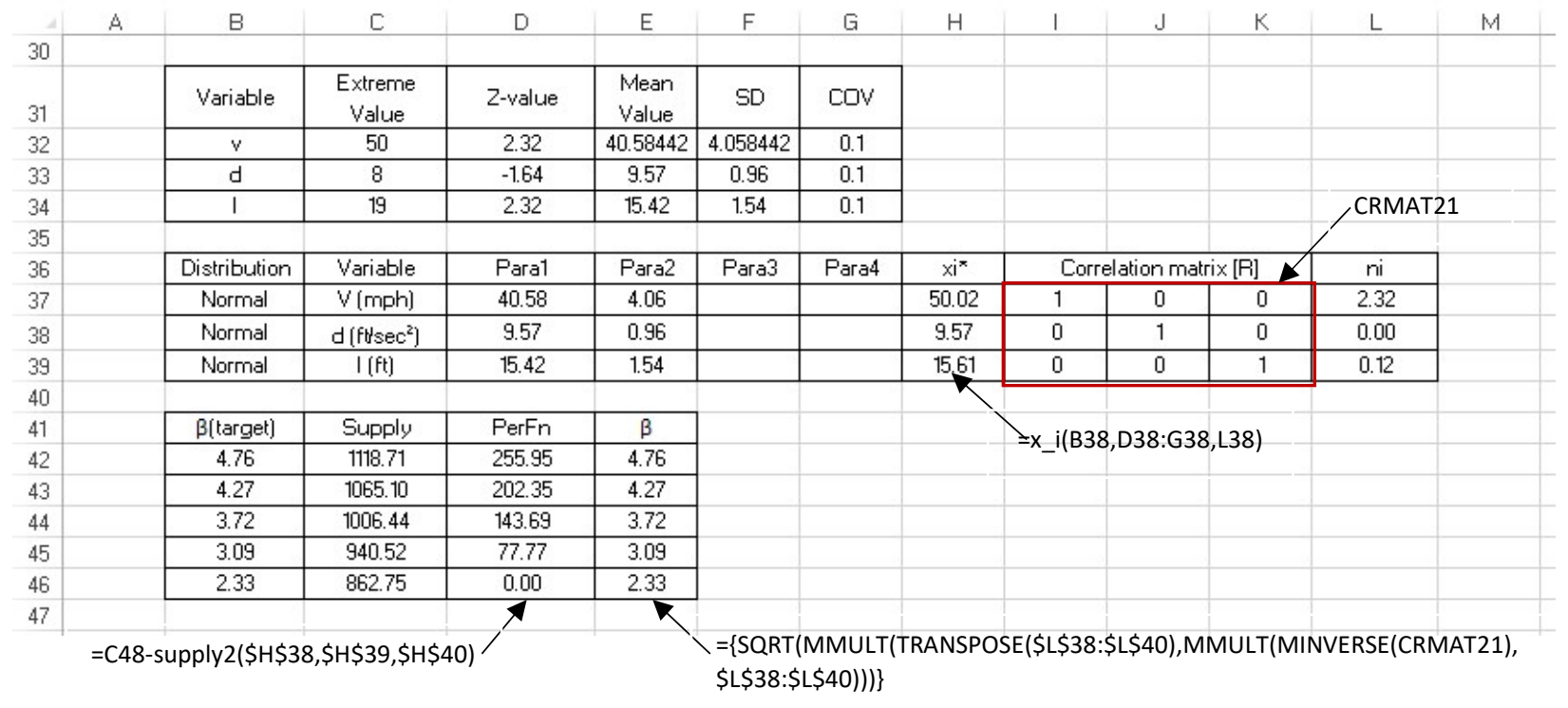

Figure 7: Example of FORM for Case II, the revised model

Similar to Low and Tang (2007), the changing variables cell remained " $n$ "' but the objective was set as a changing variable to ensure that as the solver is processing the equation the supply can change. Additionally, the constraints were set so that the "PerFn" cell was 
equal to the adjacent supply minus the demand function based on column " $\mathrm{x}_{\mathrm{i}}^{*}$ ". Column " $\mathrm{X}_{\mathrm{i}}^{*}$ ", is updated for each iteration of $\mathrm{n}_{\mathrm{i}}$.

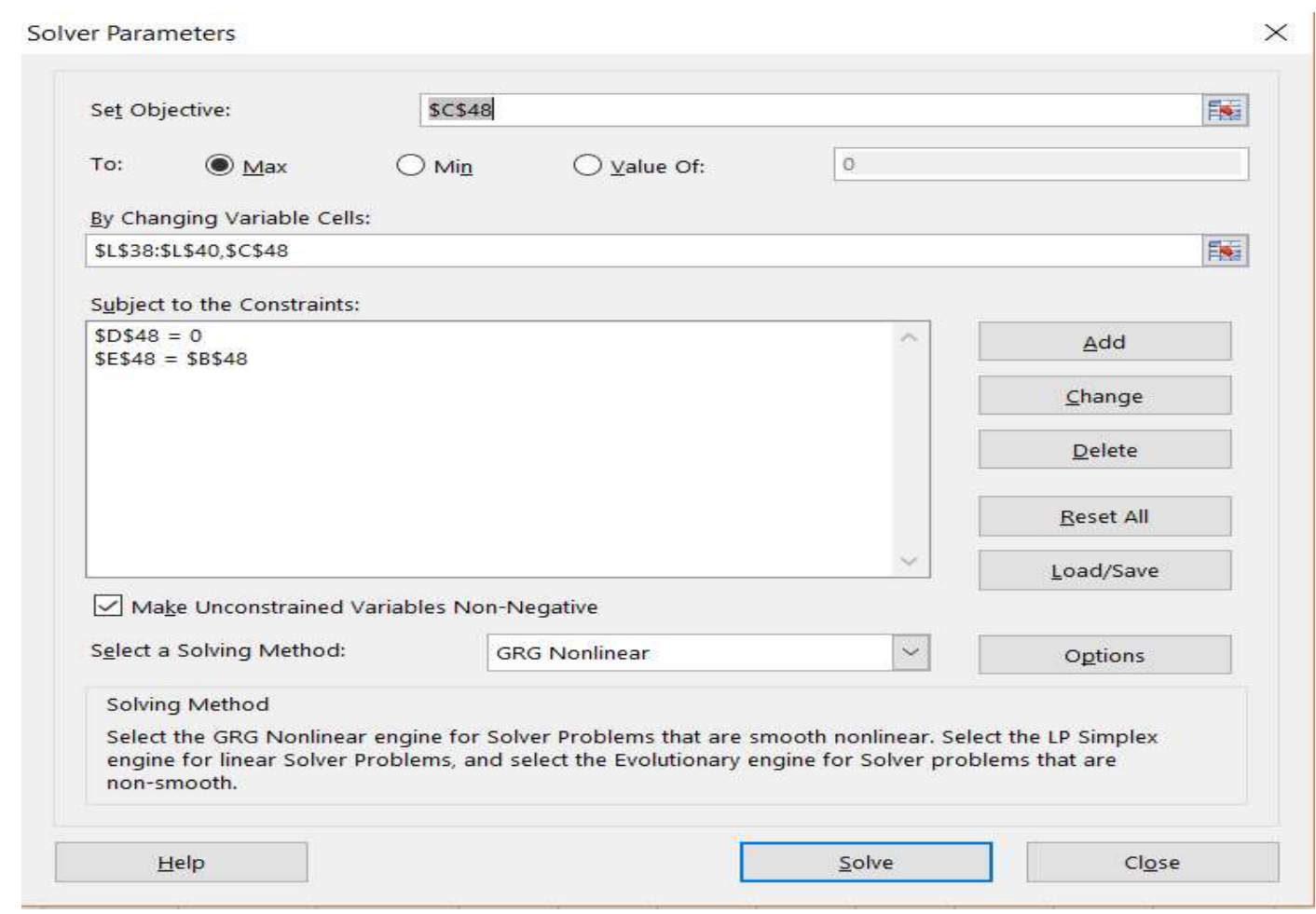

Figure 8: Solver Parametres to determine $P S D_{s}$ using FORM by Low and Tang

Function $\mathrm{x}_{-} \mathrm{i}($ Distribution,Para1,Para2,...) is a built in function in the VBA code that takes in the input of the distribution name, parameters and the changing $n_{i}$ provided by Tang and Low (2007). Function supply2(velocity,deceleration,length) is another user - defined function representing the PSD based on random variables and their extreme values in instances when the critical point is $\leq 0$. A snapshot of a sample worksheet with functions and of the SOLVER window can be found in Figure 7 and 8, respectively. 


\section{VALIDATION OF PROPOSED MODEL USING MONTE CARLO SIMULATION}

The proposed model is validated using Monte Carlo Simulation for a two-lane highway with a design speed of $80 \mathrm{mph}$. In the case of random variables, the probability distribution of a function of random variables should be normally distributed. Therefore, the analytical model corresponding to $\Delta_{c} \geq 0$ was analyzed and the mean for random variable are as follows: (1) $V=71.68 \mathrm{mph}$ and $\mathrm{L}=17.03 \mathrm{ft}$ at an assumed 99 percentile. A coefficient of variation of 0.05 for $V$ and $L$ corresponding to a standard deviation of 3.57 and 0.85 , respectively. For a reliability index of $\beta=2.33\left(\mathrm{P}_{\mathrm{f}}=1 \%\right)$, the required safety margin was equal to $2991.06 \mathrm{ft}$ with $E[G]=732.46 \mathrm{ft}$ and $\sigma_{\mathrm{f}}=314.77 \mathrm{ft}$.

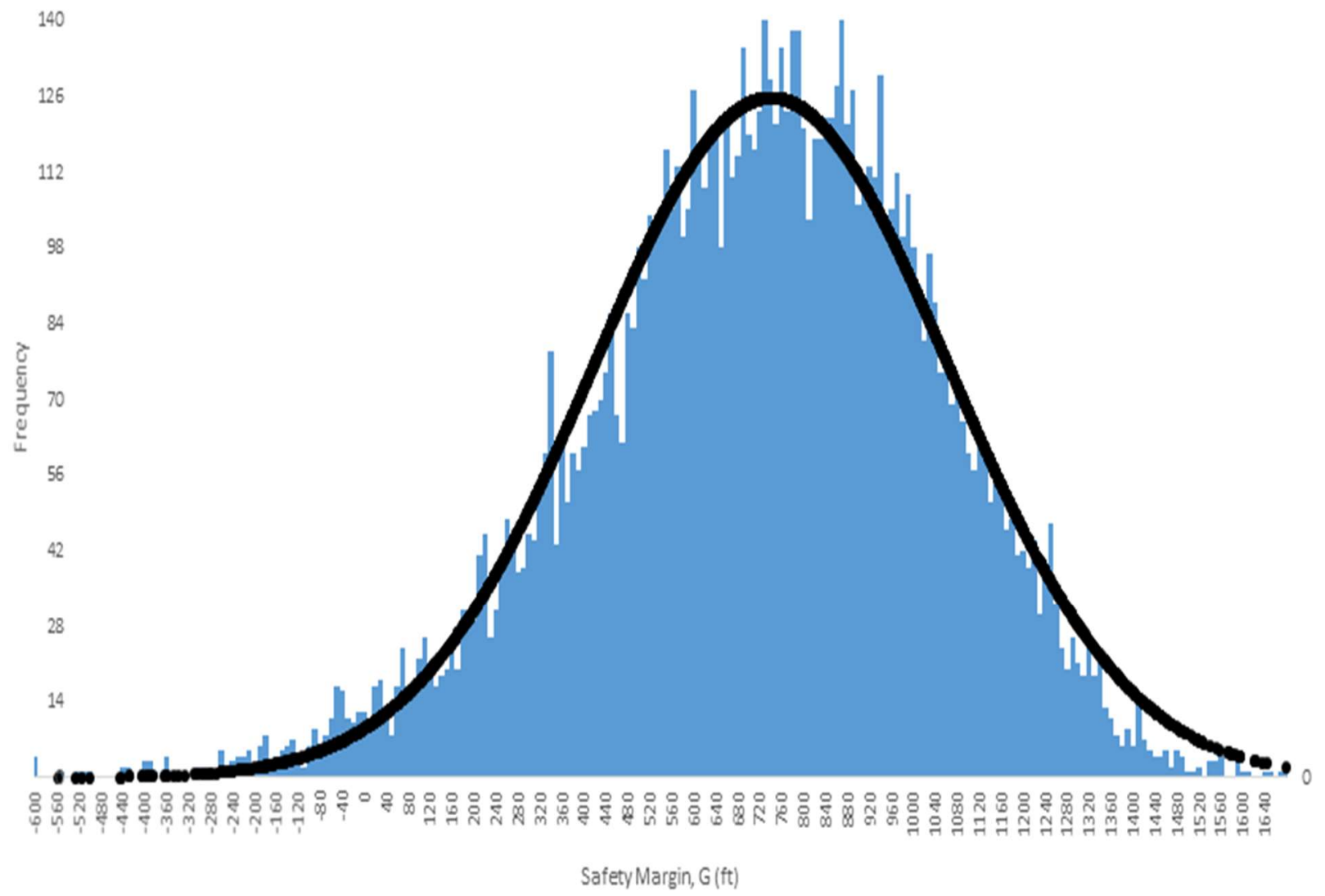

Figure 9: Histogram of Monte Carlo simulations and the probability distribution of the Monte Carlo Simulation for PSD (E[G]=717.52 ft, of $=317.41 \mathrm{ft}$ and $\beta=2.26)$ 
A Monte Carlo Simulation was performed using the aforementioned data by generating random variables corresponding to their respective means and standard deviation. A histogram was created to show the distribution of randomly generated random variables alongside the probability distribution of the safety margin $\mathrm{G}$ as seen in Figure 9. Clearly the safety margin operates under a normal distribution with a reliability index equivalent to $2.26\left(P_{\mathrm{f}}=0.87 \%\right)$ with a mean and standard deviation of $E[G]=717.52 \mathrm{ft}$ and $\sigma_{\mathrm{f}}=$ $317.41 \mathrm{ft}$. The probability distribution of Monte Carlo Simulation validate the proposed model and the function $\mathrm{G}$ has a probability distribution that is normally distributed 


\section{APPLICATION OF RELIABILITY ANALYSIS}

When designing, it is important to provide adequate PSD for an individual probability of failure. For a probability of failure of $0.01\left(\mathrm{P}_{\mathrm{f}}=1 \%\right)$, a design speed corresponding to 60 $\mathrm{mph}$, and using the data provided in Table 5 the PSD can be calculated using the 3 types of reliability analysis i.e. FOSM, AFOSM and FORM. As previously discussed, the data inputs relied on using extreme values provided by AASHTO and other literature. Additionally, the coefficient of variation was set to a constant 0.01 for all random variables and it was assumed that there was no correlation amongst the random variables. For a design speed of $60 \mathrm{mph}$, Case II governs.

For $P_{f}=0.01$, and following the steps outlined in Section 6 of this report for executing FOSM, AFOSM and FORM, the required sight distance along a 2-lane highway are $1292.91 \mathrm{ft}, 1394.24 \mathrm{ft}$, and $1395.10 \mathrm{ft}$, respectively. It is quite evident that FOSM and FORM create an upper bound and lower bound. Moreover, AFOSM and FORM are in agreeance with each other.

AFOSM and FORM accuracy depends on whether the function is close to a linear function or not. For Case II, the function stays true to its linearity and can be depended on for accuracy. As for efficiency, FORM is simply the more intuitive approach and just as accurate as the AFOSM method. AFOSM requires a greater degree of computation of the first derivatives, which can be lengthy depending on the performance function. 


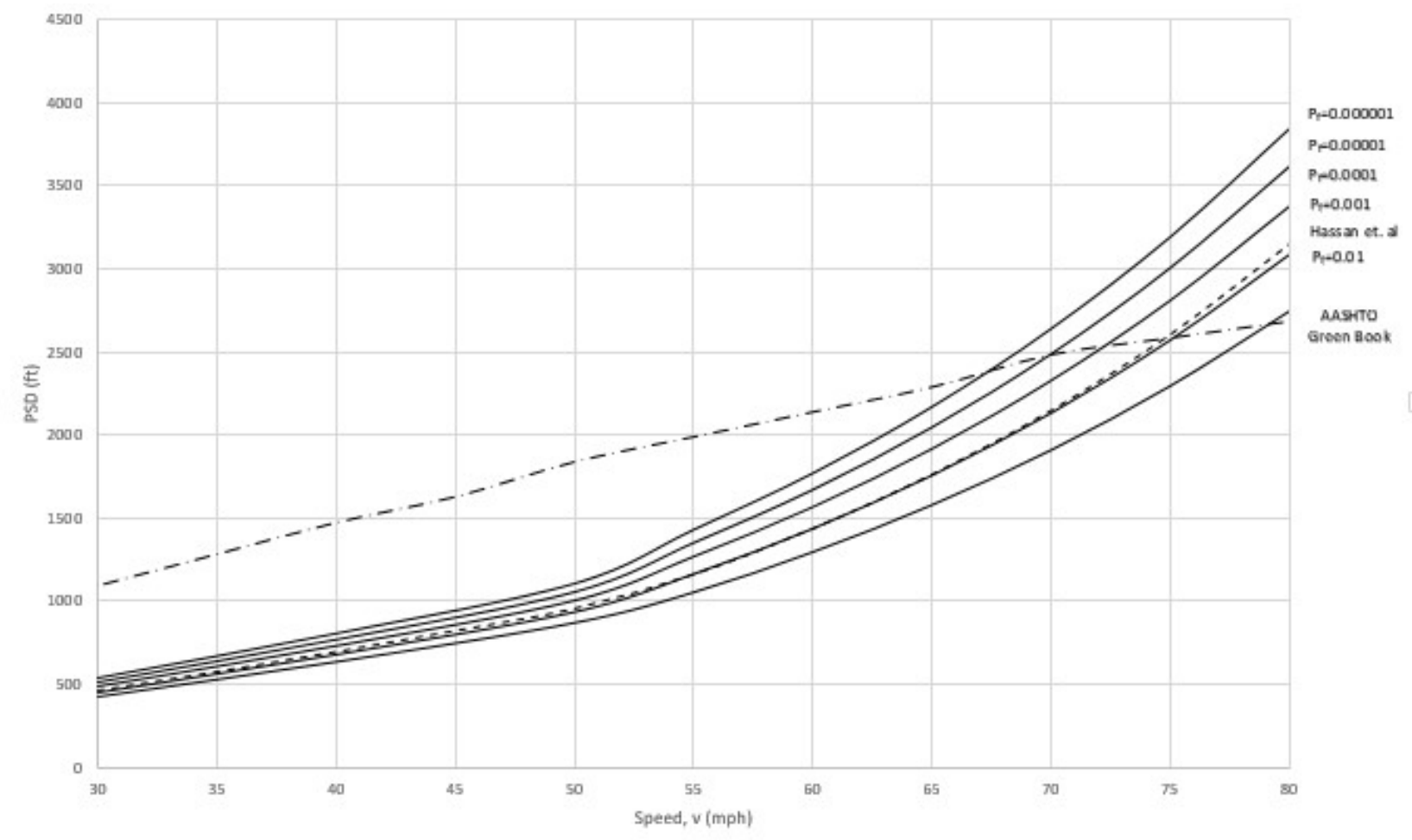

Figure 10: Required passing sight distance for a user-specified probability of failure, $P f$, for a coefficient of variation $=0.10$ (FOSM)

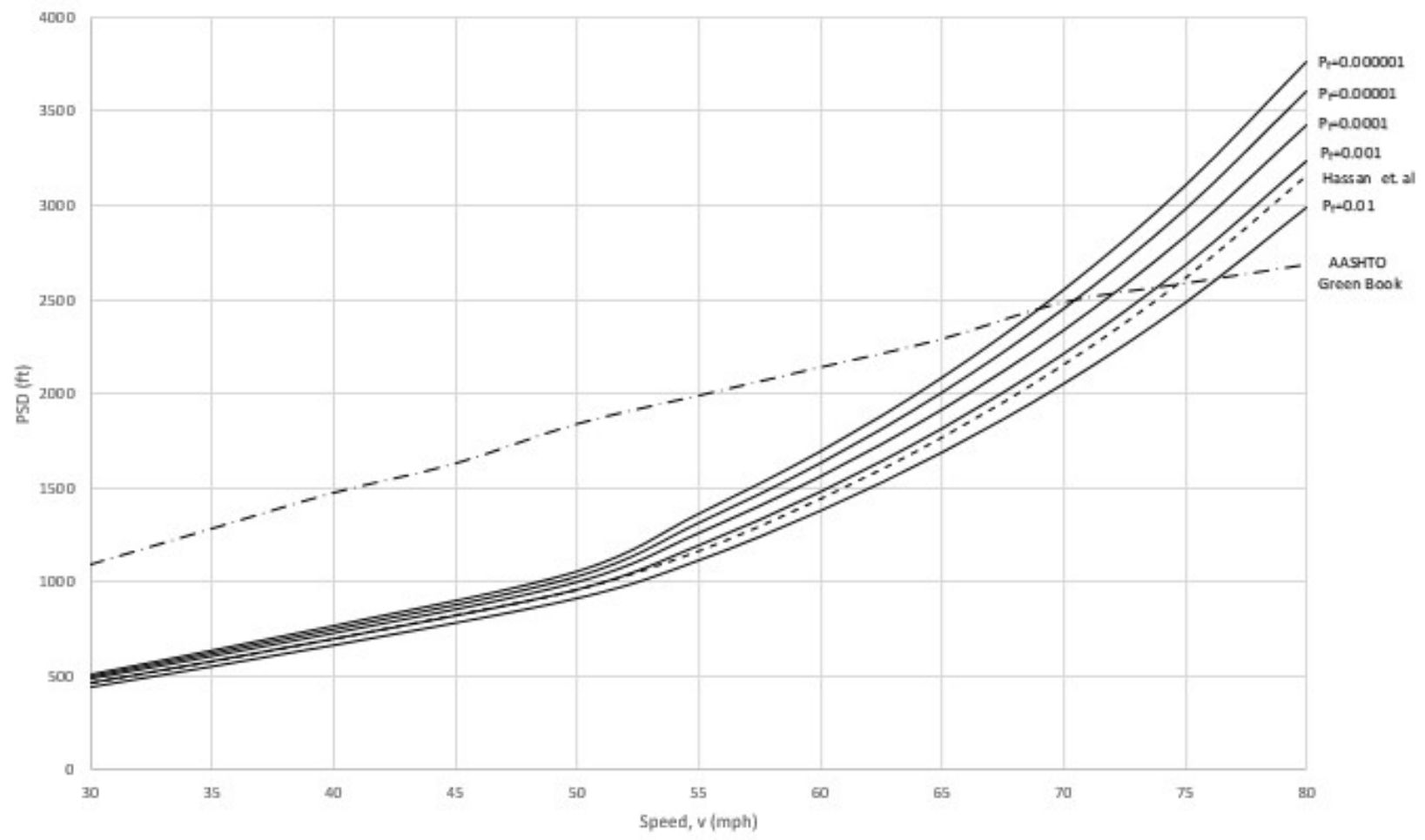

Figure 11: Required passing sight distance for a user-specified probability of failure, Pf, for a coefficient of variation $=0.05$ (FOSM) 


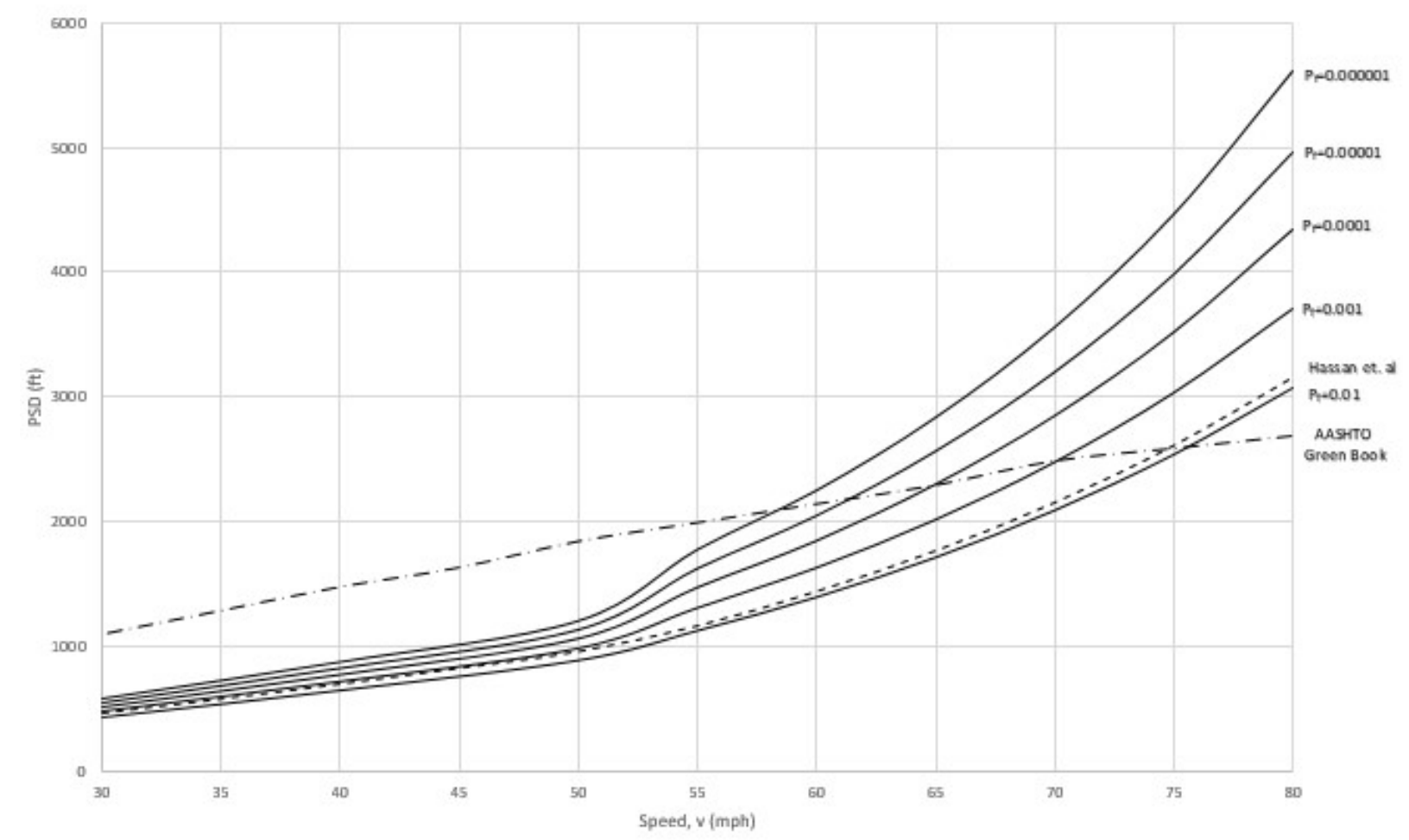

Figure 12: Required passing sight distance for a user-specified probability of failure, $P f$, for a coefficient of variation $=0.10$ (AFOSM)

Nevertheless, for a conservative design it is important to take the value corresponding to the greatest PSD, which in this case is FORM. An example of a design speed graph that relates design speed required passing sight distance and the probability of failure can be found in Figure 10 and 11 using FOSM. For a lower $\mathrm{P}_{\mathrm{f}}$, a higher required passing sight distance is needed to meet the reliability index. For example, for a coefficient of variation equal to 0.10 at a design speed of $70 \mathrm{mph}$, the required passing sight distance required varies from $1909.01 \mathrm{ft}$ to $2636.21 \mathrm{ft}$. These passing sight distances were attained using FOSM and vary for a probability of failure of $1 \%$ to $0.0001 \%$, respectively. 


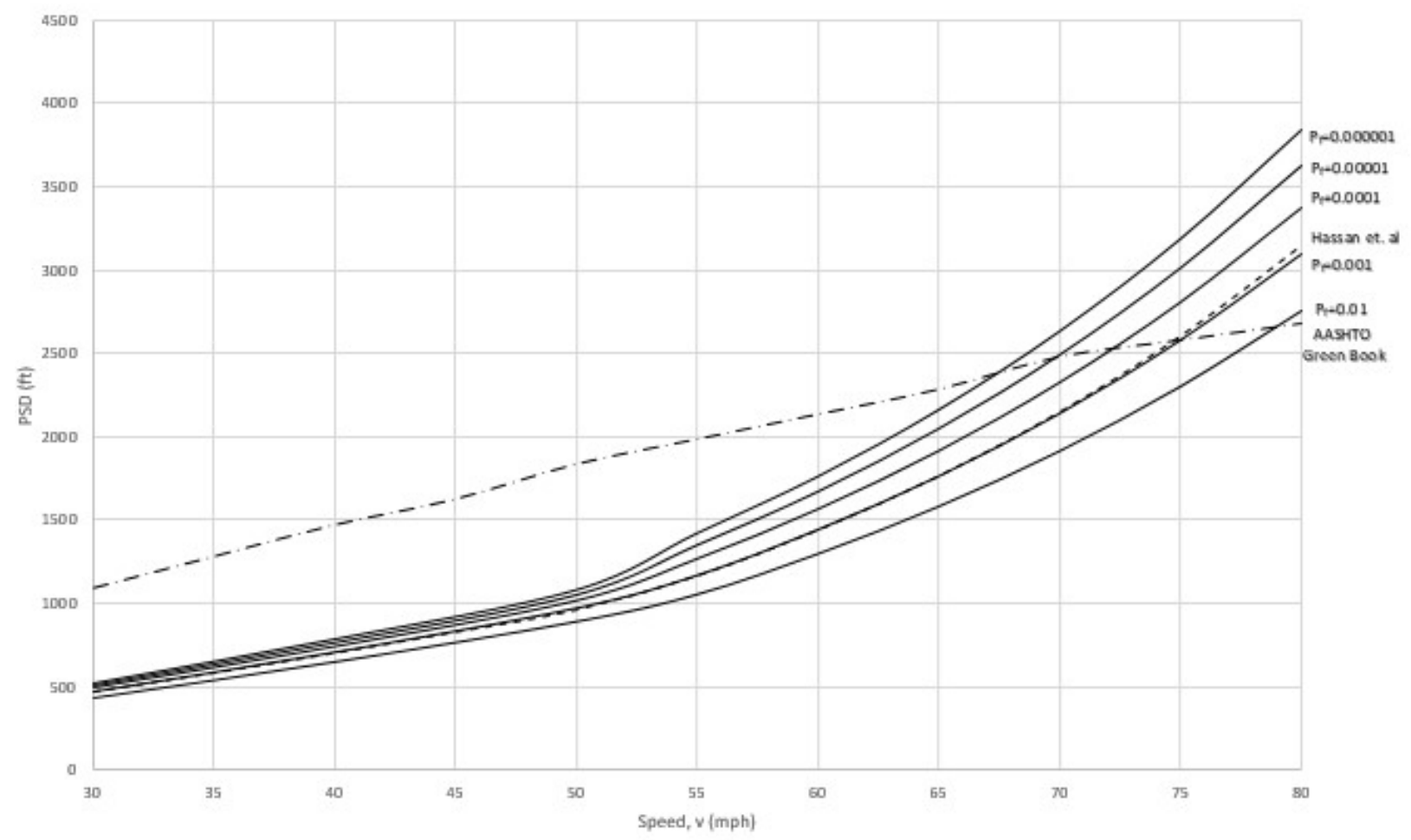

Figure 13: Required passing sight distance for a user-specified probability of failure, Pf, for a coefficient of variation $=0.05$ (AFOSM)

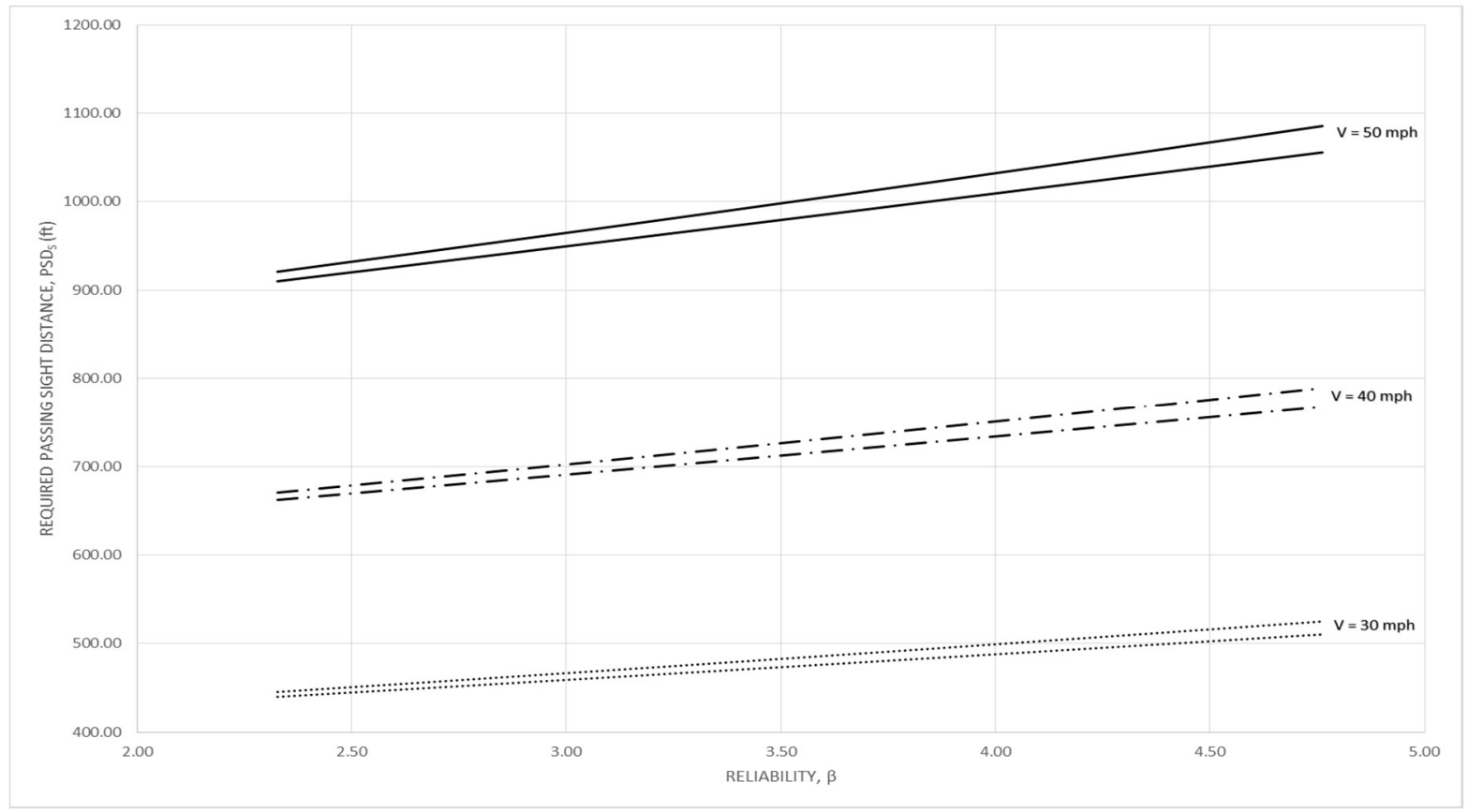

Figure 14: Required passing sight distance for a user-specified probability of failure, Pf, for a coefficient of variation $=0.05$ (FORM) 
Design speed graphs for AFOSM in Figure 12 and 13. AFOSM outputs greater overall required passing distance for all speeds and probabilities of failure. Therefore, it is important that the designer use AFOSM as it represent a more accurate design point concerning the reliability index. FORM graphs for Case II have not been provided as the difference in $\mathrm{PSD}_{\mathrm{su}}$ is anywhere from 0 to $2 \mathrm{ft}$. Therefore, FORM in this case was only used to corroborate the values attained in AFOSM. The values obtained in AFOSM for Case II are reasonable as the performance function is linear and accuracy tends to be improved in the case of AFOSM. However, FORM does provide a quicker more efficient way of obtaining the $\mathrm{PSD}_{\text {su }}$ overall. Interestingly enough, the same can not be said for Case I.

Applying the procedure outlined previously for FOSM, AFOSM and FORM the values can be found in Table 7. It is evident that each method are somewhat in agreeance with each other but there is still a significant difference between all three values. A graphical representation can be seen in Figure 14. The variation ranges are not significant but are definitely more pronounced in Case I versus Case II. It is ideal in this case to take the higher of the PSDsu for a more conservative design which is why only full design graphs are provided for AFOSM. The reason for this variation is the loss of accuracy when performing a reliability analysis on Case I due to the loss of linearity in Case I. Case I is a power function that will result in a less linear function when transformed to standard variables. 
Table 7: $P S D_{s}$ for $30 \mathrm{mph}$ for FOSM, AFOSM, and FORM

\begin{tabular}{|l|l|l|l|l|l|l|}
\hline $\mathrm{V}$ & COV & $\mathrm{pf}$ & $\beta$ & FOSM & AFOSM & FORM \\
\hline \multirow{5}{*}{30} & 0.01 & 2.33 & 442.85 & 445.81 & 440.13 \\
\cline { 3 - 7 } & 0.001 & 3.09 & 464.61 & 469.88 & 461.63 \\
\cline { 3 - 7 } & 0.0001 & 3.72 & 482.61 & 490.33 & 479.63 \\
\cline { 3 - 7 } & & 0.00001 & 4.27 & 498.30 & 508.60 & 495.50 \\
\cline { 3 - 7 } & 0.000001 & 4.76 & 512.39 & 525.37 & 509.89 \\
\cline { 3 - 7 } & 0.01 & 2.33 & 418.1836 & 428.19 & 415.93 \\
\cline { 3 - 7 } & 0.1 & 0.001 & 3.09 & 454.1269 & 472.57 & 453.12 \\
\cline { 3 - 7 } & 0.0001 & 3.72 & 483.8462 & 511.75 & 484.59 \\
\cline { 3 - 7 } & 0.00001 & 4.27 & 509.7629 & 548.11 & 512.56 \\
\cline { 3 - 7 } & & 0.000001 & 4.76 & 533.0454 & 582.84 & 538.10 \\
\hline
\end{tabular}

The design graphs also contain AASHTO design values and a graphical representation of the proposed model by Hassan et al.(1996). It is evident that AASHTO design values are too conservative especially on the lower end of the speed spectrum. For evaluation purposes, AASHTO specifies a required sight distance of $1090 \mathrm{ft}$. while Hassan et al. require a deterministic passing sight distance of $490 \mathrm{ft}$. Even for a very low probability of $0.0001 \%(\beta=4.76)$, the required passing sight distance amounts to no more than 582.84 $\mathrm{ft}$. as can be seen in Table 6. In contrast, at higher values for speed the required passing sight distance seems to fall short and in particular when speeds are greater than $55 \mathrm{mph}$. When using these design graphs it is important to use a design speed that is representative of the particular roadway in question.

\subsection{Example of Passing Sight Distance}

These design graphs are meant for a particular speed that tend to be higher in nature than the posted speed limit, especially in rural areas. For example, the posted speed limit may be set at $40 \mathrm{mph}$ but in actuality the speed at which the passing maneuver may be closer to $50 \mathrm{mph}$. For an existing PSD criteria, AASHTO requires a minimum of $1470 \mathrm{ft}$. 
A study can be done on this particular roadway to determine the actual speed and the associated mean and standard deviation. Assuming the actual speed is $50 \mathrm{mph}$ with a coefficient of variation of 0.1 , the $\mathrm{PSD}$ required for a $\mathrm{Pf}=1 \%$ is approximately $645 \mathrm{ft}$. Therefore, passing lane markers can be extended further where only $645 \mathrm{ft}$ of passing sight distance is available, thereby increasing the efficiency and productivity of said roadway. The same can be said if there is a roadway in question that has been experiencing more than expected accidents. This may be true when the speed of the actual passing maneuver is higher. By choosing a low probability of failure, the designer can ensure that adequate passing sight distance is provided. 


\section{CONCLUSION}

The paper offers three methods of reverse reliability analysis for PSD for two-lane highways. The model presented by Hassan et al. (1996) in particular was analyzed using FOSM, AFOSM and FORM. The methods used, varied in efficiencies with AFOSM being the most comprehensive method and FORM being the most intuitive. Design speed graphs are provided which can be used to design two-lane highways and even improve upon existing two-lane highways. The preceding information can be used for improvements in efficiency relating to lower speeds and improvements in safety for higher speeds. From the research, it is concluded that:

1. FOSM result in lower values for required passing sight distances for all coefficient of variations analyzed. FOSM is the easiest of the three to perform a reliability analysis and therefore the most probably point corresponding to a reliability index, $\beta$, is potentially less accurate especially when the performance function is not linear.

2. When there is no correlation between the variables, AFOSM and FORM output similar results at lower and higher speeds. Differences in the required passing sight distance are minimal in lower and higher speeds, and the results attained from both AFOSM and FORM are more accurate. Both methods support each other and can therefore be used in practice when designing 2-lane highways.

3. FORM provides an easier, much more efficient way of performing a reliability analysis. Using the ellipsoid approach in conjunction with EXCEL SOLVER, Low and Tang (2007) have provided a much more intuitive approach to reliability analysis. Not only is FORM able to perform a reliability analysis on normally 
distributed random variables but also Log, Triangular, Gamma etc. distributions and it provides an easy way to update correlation between variables without having to perform a transformation of correlated variables into a space where there is no correlation.

4. Current AASHTO requirements for passing sight distance are too conservative at lower speeds and too low at higher speeds. The model proposed by Hassan et al. offers an improved model than the existing AASHTO model, which is important for the efficiency and safety of 2-lane highways. It is possible that an existing 2-lane highway will be over-designed at lower speeds or an existing highway does not meet the required PSD at higher speeds.

5. There is a need for further research and a creation of a database that records important design variables and their variability related to passing sight distance such as vehicles speed, vehicle length, perception-reaction time to abort a pass, deceleration and headway. Such a database, can be used to perform a reliability analysis where the values of the valuables are anything but deterministic and in fact, random.

Under the assumption that the performance function is normally distributed, no assumption needs to be made of the distribution of the random variables that has been validated using Monte Carlo Simulation.. 


\section{APPENDIX}

Sample Calculations

FOSM:

$$
\begin{gathered}
Z=S_{S u}-S_{d} \\
E[Z]=S_{S u}-E\left[S_{d}\right] \\
S_{S u}=E[Z]+E\left[S_{d}\right]
\end{gathered}
$$

Where

$$
E[Z]=\beta \sigma_{Z}
$$

And

$$
\begin{gathered}
\sigma_{Z}=\sqrt{\operatorname{var}[Z]} \\
\operatorname{var}[Z]=\sum_{i=1}^{n}\left(\frac{\partial f}{\partial X_{i}}\right)^{2} \sigma_{x_{i}}^{2}+\sum_{i \neq j}^{n} \sum_{j \neq i}^{n} \frac{\partial f}{\partial X_{i}} \frac{\partial f}{\partial X_{j}} \operatorname{Cov}\left(X_{i}, X_{j}\right) \\
\operatorname{var}[Z]=\left(\frac{\partial f}{\partial V}\right)^{2} \sigma_{V}^{2}+\left(\frac{\partial f}{\partial L_{p}}\right)^{2} \sigma_{L p}^{2}
\end{gathered}
$$

Where

$$
\frac{\partial f}{\partial V}=\frac{5.86 V+1.99 L_{p}}{14.91-0.1 V}+\frac{2.93 V^{2}+1.99 V L_{p}}{0.1(14.91-0.1 V)^{2}}
$$

Simplified

$$
\frac{\partial f}{\partial V}=\frac{-2930 V^{2}+873726 V+296709 L_{p}}{(10 V-1491)^{2}}
$$




$$
\frac{\partial f}{\partial L_{p}}=-\frac{1.99 L_{p}}{0.1 V-14.91}
$$

For a mean value speed of $55 \mathrm{mph}$ with a COV of 0.5 sample calculations will be performed $\beta=3.09$.

\begin{tabular}{|c|c|c|c|c|c|}
\hline Variable & $\begin{array}{c}\text { Extreme } \\
\text { Value }\end{array}$ & Z-value & Mean Value & SD & COV \\
\hline $\mathrm{V}$ & $55 \mathrm{mph}$ & 2.32 & $49.28 \mathrm{mph}$ & 2.46 & 0.05 \\
\hline $\mathrm{Lp}$ & $19 \mathrm{ft}$ & 2.32 & $17.03 \mathrm{ft}$ & 0.85 & 0.05 \\
\hline
\end{tabular}

$$
\begin{gathered}
\frac{\partial f}{\partial V}=\frac{-2930(49.28)^{2}+873726(49.28)+296709(17.03)}{[10(49.28)-1491]^{2}}=41.15 \\
\frac{\partial f}{\partial L_{p}}=-\frac{1.99(17.03)}{0.1(49.28)-14.91}=3.39
\end{gathered}
$$

\begin{tabular}{|c|c|c|c|c|c|c|c|}
\hline$\beta$ & $\partial f / \partial V$ & $\partial f / L P$ & Var [Z] & $\sigma$ & $E[Z]$ & $E\left[S_{d}\right]$ & $S$ \\
\hline 1.65 & \multirow{5}{*}{41.15} & \multirow{5}{*}{3.39} & \multirow{5}{*}{10288.12} & \multirow{5}{*}{101.43} & 167.05 & \multirow{5}{*}{880.23} & 1047.28 \\
\hline 2.33 & & & & & 236.03 & & 1116.26 \\
\hline 3.09 & & & & & 313.31 & & 1193.54 \\
\hline 3.72 & & & & & 377.20 & & 1257.43 \\
\hline 4.27 & & & & & 432.92 & & 1313.15 \\
\hline
\end{tabular}

$$
\operatorname{var}[Z]=(41.15)^{2}(2.46)^{2}+(3.39)^{2}(0.85)^{2}=10288.12 f t^{2}
$$

$$
\begin{gathered}
\sigma_{F}=\sqrt{\operatorname{var}[F]}=101.43 \mathrm{ft} \\
E[Z]=\beta \sigma_{F}=(3.09)(101.43)=313.13 \mathrm{ft} \\
E\left[S_{d}\right]=-\frac{2.93(49.28)^{2}+1.99(49.28)(17.03)}{0.1(49.28)-14.91}=880.23 \mathrm{ft} \\
S_{S u}=E[Z]+E\left[S_{d}\right]=880.23+313.13=1193.54 \mathrm{ft}
\end{gathered}
$$




\section{AFOSM:}

Transform $V$ and $L_{p}$ assuming random variables are normally distributed variables.

$$
U=\left(U_{V}, U_{L_{p}}\right)=\left(\frac{V-\mu_{V}}{\sigma_{V}}, \frac{L_{p}-\mu_{L_{p}}}{\sigma_{L_{p}}}\right)
$$

Or,

$$
U=\left(V, L_{p}\right)=\left(\mu_{V_{d}}+U_{V} \sigma_{V}, \mu_{L_{p}}+U_{L_{p}} \sigma_{L_{p}}\right)
$$

Therefore, the transformation function in U-space becomes:

$$
\begin{array}{r}
Z(U)=S_{s u}+\frac{2.93\left(\mu_{V}+U_{V} \sigma_{V}\right)^{2}+1.99\left(\mu_{V}+U_{V} \sigma_{V}\right)\left(\mu_{L_{p}}+U_{L_{p}} \sigma_{L_{p}}\right)}{0.1\left(\mu_{V}+U_{V} \sigma_{V}\right)-14.91}=0 \\
S_{s u}=-\frac{2.93\left(\mu_{V}+U_{V} \sigma_{V}\right)^{2}+1.99\left(\mu_{V}+U_{V} \sigma_{V}\right)\left(\mu_{L_{p}}+U_{L_{p}} \sigma_{L_{p}}\right)}{0.1\left(\mu_{V}+U_{V} \sigma_{V}\right)-14.91} \\
\frac{\partial f}{\partial U_{V}}=\frac{1.99 \sigma_{V}\left(\mu_{L_{p}}+U_{L_{p}} \sigma_{L_{p}}\right)+5.86 \sigma_{V}\left(\mu_{V}+U_{V} \sigma_{V}\right)}{\gamma} \\
-\frac{2.93 \sigma_{V}\left(\mu_{V}+U_{V} \sigma_{V}\right)^{2}+1.99 \sigma_{V}\left(\mu_{L_{p}}+U_{L_{p}} \sigma_{L_{p}}\right)\left(\mu_{V}+U_{V} \sigma_{V}\right)}{10 \gamma^{2}}
\end{array}
$$

Where

$$
\gamma=0.1\left(\mu_{V}+U_{V} \sigma_{V}\right)-149.1
$$

and

$$
\frac{\partial f}{\partial U_{L_{p}}}=\frac{1.99 \sigma_{L_{p}}\left(\mu_{V}+U_{V} \sigma_{V}\right)}{0.1\left(\mu_{V}+U_{V} \sigma_{V}\right)-149.1}
$$

The gradient of $Z(U)$ is given by 


$$
\begin{gathered}
\nabla Z(U)=\left(\frac{\partial f}{\partial U_{V}}, \frac{\partial f}{\partial U_{L_{p}}}\right) \\
|| \nabla Z(U) \|=\sqrt{\left(\frac{\partial f}{\partial U_{V}}\right)^{2}+\left(\frac{\partial f}{\partial U_{L_{p}}}\right)^{2}}
\end{gathered}
$$

At this point an iterative procedure will take place in order to determine the MPP $\mathrm{u}^{*}$ where the performance function $Z(U)$ is minimized. This procedure is seen below in the following flowchart. 


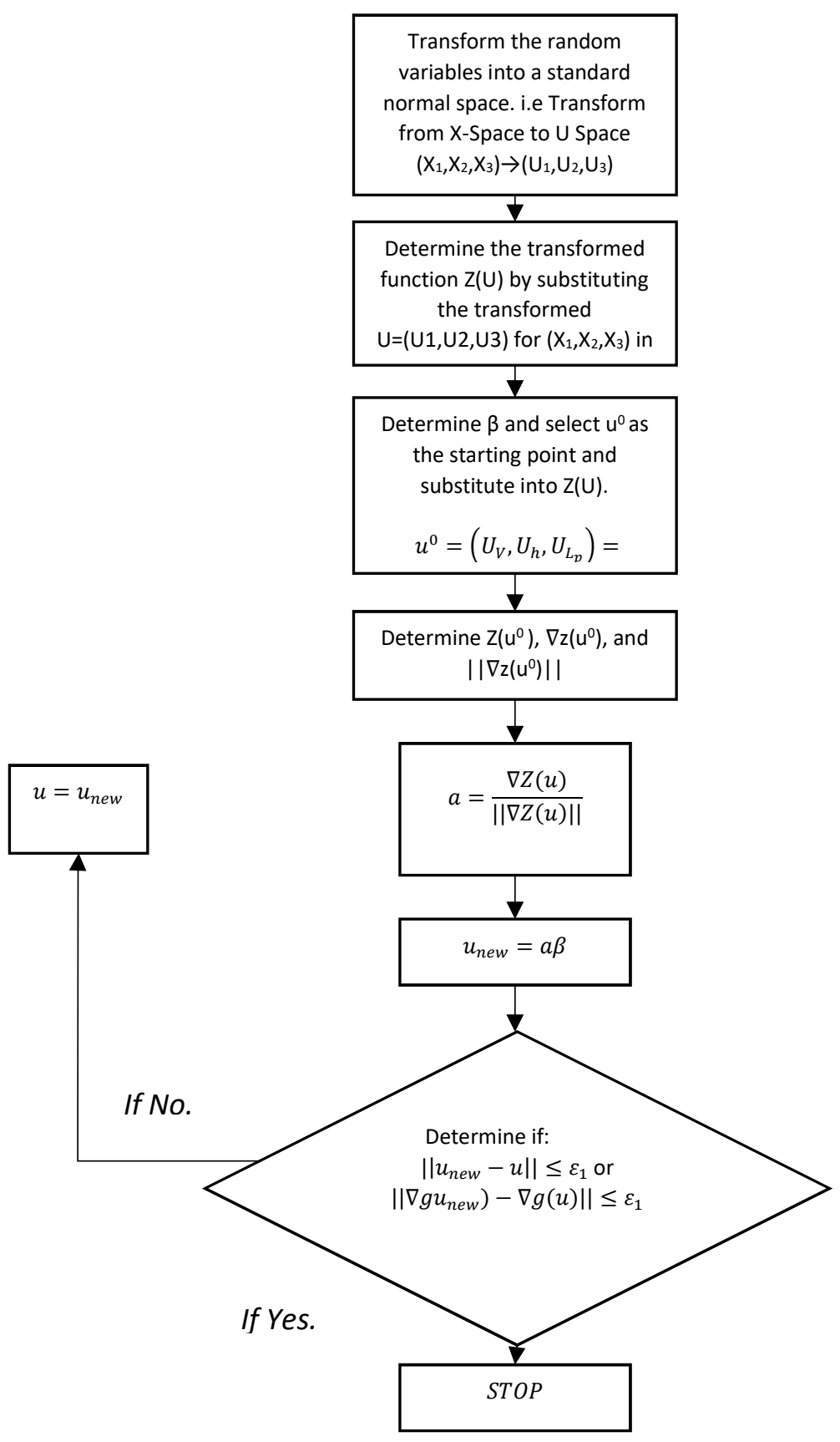

Flowchart for performing a reverse reliability method for AFOSM (adopted from Du, 2005)

For a mean value speed of $55 \mathrm{mph}$ with a COV of 0.5 sample calculations will be performed $\beta=3.09$. 


\begin{tabular}{|c|c|c|c|c|c|}
\hline Variable & $\begin{array}{c}\text { Extreme } \\
\text { Value }\end{array}$ & Z-value & Mean Value & SD & COV \\
\hline $\mathrm{V}$ & $55 \mathrm{mph}$ & 2.32 & $49.28 \mathrm{mph}$ & 2.46 & 0.05 \\
\hline $\mathrm{L}_{p}$ & $19 \mathrm{ft}$ & 2.32 & $17.03 \mathrm{ft}$ & 0.85 & 0.05 \\
\hline
\end{tabular}

Iteration 0: Start at $\left(U_{v}, U_{\llcorner p}\right)=(0,0)$

Find Su:

$$
\begin{gathered}
S_{s u}=-\frac{2.93\left(\mu_{V}+U_{V} \sigma_{V}\right)^{2}+1.99\left(\mu_{V}+U_{V} \sigma_{V}\right)\left(\mu_{L_{p}}+U_{L_{p}} \sigma_{L_{p}}\right)}{0.1\left(\mu_{V}+U_{V} \sigma_{V}\right)-14.91} \\
S_{s u}=-\frac{2.93(49.28)^{2}+1.99(49.28)(17.03)}{(-9.98)} \\
S_{s u}=880.23 \mathrm{ft}
\end{gathered}
$$

Find gradient:

$$
\begin{gathered}
\gamma=0.1\left(\mu_{V_{d}}+U_{V_{d}} \sigma_{V_{d}}\right)-14.91=0.1(49.28)-14.91=-9.98 \\
\frac{\partial f}{\partial U_{V_{d}}}=\frac{1.99(2.46)(17.03)+5.86(2.46)(49.28)}{(-9.98)} \\
-\frac{2.93(2.46)(49.28)^{2}+1.99(2.46)(17.03)(49.28)}{10(-9.98)^{2}}=-101.39 \\
\frac{\partial f}{\partial U_{L_{p}}}=\frac{1.99(0.85)(49.28)}{y}=-8.36
\end{gathered}
$$


The gradient of $Z(U)$ is given by

$$
\begin{gathered}
\nabla Z(U)=\left(\frac{\partial f}{\partial U_{V_{d}}}, \frac{\partial f}{\partial U_{h}}, \frac{\partial f}{\partial U_{L_{p}}}\right) \\
|| \nabla Z(U) \|=\sqrt{(-101.39)^{2}+(-8.36)^{2}}=101.73 \\
a=\frac{\nabla Z(U)}{\|\nabla Z(U)\|}=\frac{(-101.39,-8.36)}{101.73}=(-0.9967,-0.08221) \\
u_{\text {new }}=-a \beta=(-0.9967,-0.08221)(3.09)=(2.3191,0.1913)
\end{gathered}
$$

Determine if:

$$
\begin{gathered}
|| u_{\text {new }}-u \| \leq \varepsilon_{1} \text { or } \\
\left\|\nabla g\left(u_{\text {new }}\right)-\nabla g(u)\right\| \leq \varepsilon_{1}
\end{gathered}
$$

Note: After the $2 \mathrm{nd}$ and $3 \mathrm{rd}$ iterations $\left(\mathrm{U}_{\mathrm{V}}, \mathrm{U}_{\llcorner\mathrm{p}}\right)=(2.3195,0.1863)$ and $(2.3195,0.1863)$ respectively.

$$
\begin{gathered}
|| u_{\text {new }}-u\|=\|(2.3195,0.1863)-(2.3195,0.1863) \|=\sqrt{(0)^{2}+(0)^{2}}=0 \\
0 \leq \varepsilon_{1} \quad O K
\end{gathered}
$$

Now find $r$ :

$$
\gamma=0.1(49.28+2.3195 * 2.46)-14.91=-9.41
$$

Find Ssu:

$$
\begin{aligned}
& S_{\text {su }} \\
& =-\frac{2.93(49.28+2.3195 * 2.46)^{2}+1.99(49.28+2.3195 * 2.46)(17.03+0.1863 * 0.85)}{(-9.41)}
\end{aligned}
$$




$$
S_{s u}=1141.71 \mathrm{ft}
$$

\section{For Case I:}

The following is the MATLAB code that aided in performing a reliability analysis using FOSM, AFOSM and FORM.

syms v d ta tb I uv ud ul mv md ml sdv sdd sdl

$$
y=2.93^{*} v^{*}(\operatorname{ta}+1) \text {; }
$$

$y=\operatorname{subs}\left(y\right.$, ta, $\left.1+t b-\left(d^{*}+b^{*}(t b+2) /\left(5.88^{*} v\right)\right)\right)$;

$y=\operatorname{subs}\left(y, t b,-1+\operatorname{sqrt}\left(\left(1+11.76^{*} v^{*} \mid+17.29^{*} v^{\wedge} 2-122.74^{*} v\right) /\left(3.087^{*} d^{*} v-21.9177^{*} d\right)\right)\right) ;$

$\% \operatorname{simplify}(y)$

$\% \operatorname{vpa}(\mathrm{y}, 3)$;

$\%$ simplify(diff(y, v));

$\% \operatorname{simplify}(\operatorname{diff}(y, d))$;

$\% \operatorname{simplify}(\operatorname{diff}(y, \mathrm{I}))$;

$\% y=\operatorname{subs}\left(y, v, m v+u v^{*} s d v\right)$;

$\% y=\operatorname{subs}\left(y, d, m d+u^{*} s d d\right)$;

$\% y=\operatorname{subs}\left(y, l, m l+\right.$ ul$\left.^{*} s d l\right) ;$

\%vpa $(\mathrm{y}, 3)$

\%simplify(diff(y, uv)

$\%$ simplify(diff(y, ud)

\%simplify(diff(y, ul) 


\section{REFERENCES}

A Policy on Geometric Design of Highways and Streets. (2011). Washington: American Association of State Highway Officials.

Carlson, P., Miles, J., \& Johnson, P. (2006). Daytime High-Speed Passing Maneuvers Observed on Rural Two-Lane, Two-Way Highway: Findings and Implications.

Transportation Research Record: Journal of the Transportation Research Board, 1961, 9-15. doi:10.3141/1961-02

Du, X. (2005). First Order and Second Reliability Methods.

Fambro, D.B., K. Fitzpatrick, and R.J. Koppa. NCHRP Report 400: Determination of Stopping Sight Distance, TRM, National Research Council, Washington, DC, 1997.

Harwood D.W. and Glennon J.C. (1989). Passing Sight Distance for passenger cars and trucks. Transpn Res. Rec. 1208, 56-69.

Harwood, D. W., Gilmore, D. K., Richard, K. R., Dunn, J. M., \& Sun, C. (n.d.). NCHRP 605 - Passing Sight Distance Criteria 2008. www.TRB.org.

Hassan, Y., Easa, S., \& El Halim, A. (1996). Passing Sight Distance on Two-Lane Highways: Review and Revision. Transportation Research Part A: Policy and Practice, 30(6), 453-467. http://dx.doi.org/10.1016/0965-8564 (95)00032-1

Highway capacity manual. (2016). Washington, D.C.: Transportation Research Board of the National Academies.

Lieberman E.B. (1982). Model for Calculating Safe Passing sight ditances on two-lane rural roads. Transpn Res. Rec. 869, 70-76.

Llorca, C., Moreno, A., Sayed, T., \& García, A. (2014). Sight Distance Standards Based on Observational Data Risk Evaluation of Passing. Transportation Research Record: Journal of the Transportation Research Board, 2404, 18-26. doi:10.3141/2404-03

Low, B. K., \& Tang, W. H. (2007). Efficient Spreadsheet Algorithm for First-Order Reliability Method. Journal of Engineering Mechanics, 133(12), 1378-1387. doi:10.1061/(asce)0733-9399(2007)133:12(1378)

Polus, A., Livneh, M., \& Frischer, B. (2000). Evaluation of the passing process on twolane rural highways. Transportation Research Board, (1701).

Rillet L.R., Hutchinson B.G. and Whitney M. (1990). Mechanis of the pasing maneuver and the impact of large trucks. Transpn Res. 24A(2), 121-128. 
Singh, V., Jain, S., \& Tyagi, A. (2010). Risk and Reliability Analysis: A Handbook for Civil and Environmental Engineers. Reston, VA: ASCE.

Smith, G. N. (1986). Probability and Statistics in Civil Engineering: An Introduction. London: Collins Professional and Technical.

Van Valkenburg, G.W., and H.L. Michael. Criteria for No-Passing Zones. Highway Research Record 388, HRB, National Research Council, Washington, DC, 1972, pp3639.

Wortman, R. H., \& Matthias, J. S. (1983). An Evaluation of Driver Behavior at Signalized intersections. Final report. Washington, DC: National Research Council. 